\title{
A charging time energy fraction method for evaluating the performance of a latent thermal energy storage heat exchanger
}

\author{
Wim Beyne ${ }^{a, b}$, Kenny Couvreur ${ }^{a, b, c}$, Ilya T' Jollyn ${ }^{a, b}$, Robin Tassenoy ${ }^{a, b}$, Steven \\ Lecompte $^{\mathrm{a}, \mathrm{b}}$ and Michel De Paepe ${ }^{\mathrm{a}, \mathrm{b}}$ \\ ${ }^{a}$ Department of Electromechanical, Systems and Metal Engineering - UGent, Ghent, Belgium, \\ wim.beyne@ugent.be \\ b FlandersMake@UGent - Core lab EEDT-MP, Leuven, Belgium, www.flandersmake.be, \\ ${ }^{c}$ Research group Thermal energy in industry, Ghent University, Kortrijk, Belgium
}

\section{Abstract}

Latent thermal energy storage heat exchangers have a large potential in different processes. Implementing such a heat exchanger requires evaluating the performance of the heat exchanger in the conditions of each specific process. Therefore a method to characterize the performance of a latent thermal energy storage design would be a useful tool for designing processes. Characterization methods for heat exchangers such as the effectiveness number of transfer units method are based on the steadystate operation of the heat exchanger. However latent thermal energy storage heat exchangers cannot operate in steady state and therefore the standard methods are not applicable. The present paper develops a novel method to determine the heat transfer fluid outlet state as a function of the initial and input conditions: the charging time energy fraction method. This method is used to characterize and evaluate a latent thermal energy storage channel heat exchanger. For 26 out of 30 calibration and validation experiments, the model predicts the outlet heat transfer fluid temperature within measurement uncertainty $\left( \pm 0.15^{\circ} \mathrm{C}\right)$ during all but the initial $100 \mathrm{~s}$ of the charging process. The charging time energy fraction method is the first method available to derive a predictive model from a set of experiments for the outlet temperature of a latent thermal energy storage heat exchanger.

Keywords: Latent thermal energy storage, experimental predictive model, heat exchanger, cold storage, solid liquid phase change

\section{Highlights}

- The charging time energy fraction method is developed

- The method allows to predict the outlet state of a latent thermal energy storage heat exchanger as a function of the input conditions

- The method is used to develop a model for a specific heat exchanger

- The model's predictions are within the measurement uncertainty for the majority of the experiments 


\section{Introduction}

For almost a decade, the potential of Latent Thermal Energy Storage (LTES) has been identified [1] in a wide range of energy systems such as domestic hot water production [2,3], cold chain transport [4], heating and cooling of buildings [5] and grid level power storage [6]. However, this large potential has not yet been translated in the wide application of LTES systems with LTES only reaching full maturity for cold storage and larger scale ice or aqueous salt solutions $[7,8]$. The technological maturity is also reflected in the total installed TES capacity. In a listing of grid connected TES projects of the USA department of energy, all TES accounts for $22.4 \mathrm{MWh}$ of which $89 \%$ are molten salt thermal storage and another $9.4 \%$ chilled water or ice storage.

The mismatch between potential and application raises the question what is holding back LTES systems. To answer this question, the methods available in literature for designing or evaluating LTES systems are reviewed. Castell and Solé [9] split the design problem in three sub problems. The first issue is selecting an appropriate Phase Change Material (PCM) for the application. The second issue is selecting an enclosure method for containing the PCM and the material compatibility between the PCM and container material. The third consideration is the geometric design of the LTES system.

The first issue resolves around choosing a PCM with a phase change temperature appropriate for the application. The necessity of matching the phase change temperature to the specific application has resulted in PCMs being developed for a wide range of inlet temperatures [10-12]. Although the development of new PCMs is a continuing interest for researchers (e.g. [13]), PCM materials are commercially available in a wide temperature range (e.g. [14]).

Two types of encapsulation methods are distinguished based on the amount of PCM enclosed in each individual container: macro- and micro- encapsulated PCM [10, 15]. Both macro and micro-encapsulated PCMs are commercially available [14].

The first step in the geometric design of an LTES system is choosing a configuration type [9]. Three configurations are distinguished by Mehling and Cabeza [15] depending on the location of the heat transfer between the PCM and the surroundings. In the first type, the heat transfer occurs on the storage system's outer surface. In the second type, the heat transfer occurs on an internal surface and the heat is transferred to a heat transfer fluid (HTF). In the third type, the PCM is transported with the HTF. The design considerations are different for these three configuration [9]; the present article focusses on storage systems with heat transfer on an internal surface.

LTES systems with heat transfer on an internal surface are further categorized in three types: heat exchanger type, module type and direct contact type [9]. In the direct contact type, there is no encapsulating material between the PCM and the heat exchanger while in the first two types there is. The difference between heat exchanger and module type is in the construction of the LTES system. In module type LTES systems, modules of macro encapsulated PCM are placed in a tank in which HTF flows while in heat exchanger LTES systems the PCM modules are integrated into the tank. Heat exchanger LTES systems are the most common type and the interest of the present discussion [9].

The design question for LTES heat exchangers requires determining the interaction between the LTES heat exchanger and the process into which it is integrated [16]. For an LTES heat exchanger, the interaction with the process is through a change in HTF state between the inlet and outlet of the LTES heat exchanger. 
Furthermore, the LTES heat exchanger can interact with its surroundings through heat transfer over the boundary of the LTES system.

The straightforward method of evaluating the performance of a LTES heat exchanger into a process consists of constructing the heat exchanger and testing it with the appropriate process conditions. However, this method is too expensive if multiple designs are to be evaluated. Therefore, a model is required to evaluate a LTES heat exchanger's performance in a process as depicted schematically in Figure 1. The unavailability of such a model severely affects the cost of evaluating heat exchanger designs.

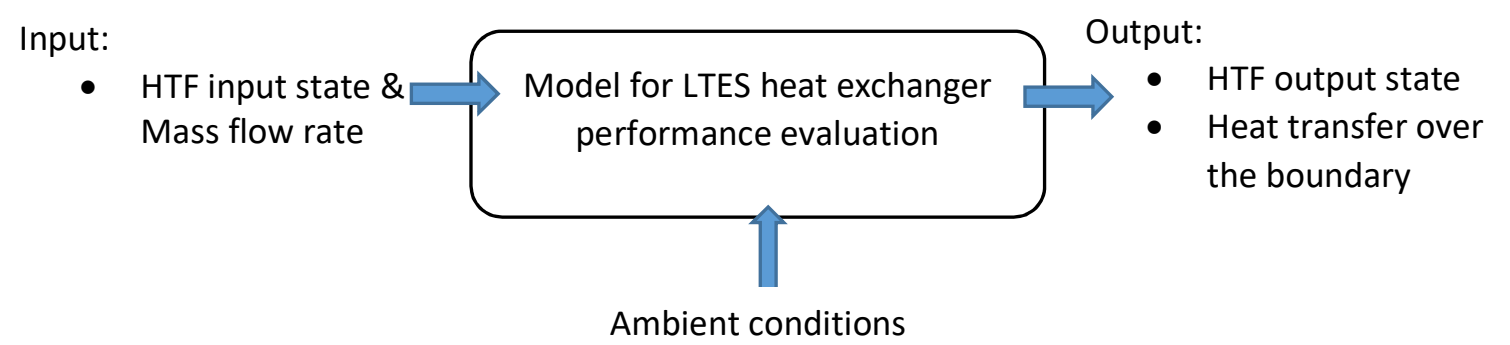

Figure 1: Schematic representation of a model which allows evaluating the performance of an LTES heat exchanger for a specific application.

The model proposed in Figure 1 should have several characteristics in order to be useful for evaluating LTES heat exchanger designs. Firstly, the model should be fitted once for general input conditions and ambient conditions and then be useful for predicting the output for process specific input and ambient conditions. The model should thus not consist of discrete data points giving the output of the LTES heat exchanger for the discrete tested input conditions but rather predict the output of the LTES heat exchangers in the entire testing range. Secondly, since the model is fitted once it should be easy to transfer and implement to engineers designing a process. Finally, the model should not be prohibitively expensive in terms of calculation time for a process simulation.

One of the most common model types for LTES heat exchangers relies on the discretized solution of the conservation laws (e.g. [17-19]). Using such a computational fluid dynamics (CFD) model directly allows determining the output for specific input conditions and thus fits the requirements of Figure 1. However, accurately describing solid-liquid phase change on the scale of a heat exchanger requires setting factors such as the mushy zone constant $[20,21]$ or a solid viscosity [22]. These factors are dependent on the geometry and operating conditions of the heat exchanger [20-22] and therefore require fitting to experimental results. The computational time required for these models can make this fitting unfeasible for full heat exchangers and therefore these coefficients are fitted for phase change under constant boundary conditions [20-22]. Furthermore, using the model requires transferring the model code or implementing the model directly into a process simulation. Implementing such a model in a process simulation is expensive in terms of calculation time. CFD models are thus a useful method for designing LTES heat exchangers, however they do not allow to derive a predictive model from a set of experiments which can be implemented in process simulations for different applications.

The usefulness of CFD models for LTES heat exchangers is not different from steady-state heat exchangers. CFD is a useful tool for designing heat exchangers [23-25] however not for direct implementation in process simulation $[23,26]$. The results of a CFD calculation however can be reduced to an overall heat transfer coefficient $[24,25]$ which in combination with effectiveness-number of transfer units $(\epsilon-N T U)$ or 
logarithmic mean temperature (LMTD) method provide a model for the heat exchanger. Instead of using results from CFD calculations, techniques based on experimental measurements such as the Wilson plot method [27] exploit the same data reduction method using an overall heat transfer coefficient.

Data reduction of (numerical) experiments on heat exchangers is thus based on an application of the $\epsilon$ NTU or LMTD method. However, the NTU or LMTD method are not applicable to LTES heat exchanger since they are based on the assumption of a heat exchanger in steady state [28, 29]. An LTES heat exchanger stores energy by changing the internal energy of a storage material, therefore it cannot operate in steady state.

The lack of an appropriate model for LTES heat exchangers leads to an issue both when sizing and rating these heat exchangers. With regard to the sizing problem, the design of the surfaces is crucial for the LTES power output since most PCMs have a low thermal conductivity [15]. There are several solutions for enhancing the PCM such as fins, nano additives, metal foams, graphite foams and metal inserts [30]. The results of the enhancement studies are often predictive models for e.g. the charging time [31-33], dimensionless temperature [33] or an average heat transfer coefficient [34-36] expressed as a function of dimensionless numbers. However, these studies apply a constant boundary condition (e.g. [34-38]) while the boundary condition in a LTES heat exchanger changes both in time and along the flow length of the heat transfer fluid. Without the LMTD or $\in$-NTU method, the correlations derived for a constant boundary condition cannot be expanded to a full heat exchanger and therefore do not allow defining a predictive model for LTES heat exchangers.

Without the LMTD and $\epsilon$-NTU method, a set of experiments cannot be reduced to an overall heat transfer coefficient nor can the predictive models under constant boundary conditions be extended to heat exchangers. As a result, the output of studies on LTES heat exchangers is often limited to a graphical representation of the outlet temperature and a set of selected performance indicators for a discrete number of operating points (e.g. [39, 40]).Three model types attempt to fill the gap left by the LMTD and $\epsilon$-NTU method by predicting aspects of the heat exchanger output. These three model types found in literature are average effectiveness-number of transfer unit models [41-44], state of charge-effectiveness models [45] and models for the charging time $[46,47]$.

The average effectiveness-number of transfer unit models allows determining the average outlet temperature of a HTF during phase change [41-44]. In the model, the outlet temperature is determined by the heat exchanger effectiveness, which is defined as the ratio of the temperature difference between inlet and outlet to the temperature difference between the phase change temperature and the HTF inlet temperature. The average effectiveness is than predicted as a function of the mass flow rate. This model has been successfully applied to shell and tube LTES heat exchangers [41-44], however it only predicts an aspect of the output namely the average outlet temperature during phase change. The output temperature during the entire charging cycle is not determined by the average effectiveness correlation.

State of charge effectiveness models have been developed as control models for ice storage [45]. The model relies on measuring the volumetric state of charge or the volume of water which has solidified. The effectiveness is defined similar as in the approach above. The ice storage is charged and the effectiveness is determined as a function of the measured state of charge. These curves are determined for discrete mass flow rates and used to predict the outlet temperature for partial charging cycles. 
The state of charge effectiveness model requires measuring the amount of PCM which has solidified or the latent state of charge. There are multiple methods for measuring the state of charge of a LTES heat exchanger however there is no generally applicable method [48]. Therefore, this type of model cannot be fitted for all LTES heat exchanger designs. Furthermore, for a predictive model, the state of charge should be estimated by the model itself and not measured.

Charging time only concerns a specific aspect of the outlet state, however it is an often reported as a performance indicator. Two versions of the charging time are reported: the total charging time concerning the total stored heat [49-53] and the phase change time related to the latent stored heat $[18,19,40,54-$ 62].

The charging time is of particular interest since Raud et al. [46] formulated a correlation of the charging time as a function of HTF inlet temperature and mass flow rate. Beyne et al. [47] reformulated the correlation and successfully compared it to datasets in literature. The correlation was fitted to a specific LTES heat exchanger and allowed predicting the charging time as a function of HTF mass flow rate and inlet temperature. A predictive model for the charging time is available which can be experimentally fitted. However similarly as with the effectiveness-number of transfer units model, the model only predicts one aspect of the outlet state and not the outlet state as a function of time. A model as represented in Figure 1 would be beneficial for evaluating LTES heat exchanger designs in specific process conditions and would thus aid the wider application of LTES systems. However, such a model is not available in literature since the models in literature only predict aspects of the outlet state of a LTES heat exchanger. The present article formulates the charging time energy fraction method which allows to develop and calibrate a performance model for LTES heat exchangers. The model is experimentally fitted and used to predict the performance of a specific LTES heat exchanger. It is the only method available in literature with allows to determine a predictive model for the outlet temperature of LTES heat exchangers as a function of time without resorting to CFD simulations.

\section{The charging time energy fraction method}

The first law of thermodynamic is applied to a control volume encompassing the entire LTES heat exchanger, which is shown schematically on Figure 2. This control volume thus contains three materials: PCM, HTF and the container material. The properties of these materials as well as the LTES heat exchanger geometry are assumed to be known. As a result the internal energy of the LTES heat exchanger $U$ can be determined as the sum of the internal energy of the PCM $U_{P C M}$, container $U_{c}$ and HTF $U_{\text {HTF }}$ as a function of the local state of the LTES heat exchanger (Equation 1).

$$
\begin{aligned}
U & =U_{P C M}+U_{C}+U_{H T F} \\
& =\int_{P C M} u_{P C M}(\text { state }) d m+\int_{C} u_{C}(\text { state }) d m+\int_{H T F} u_{H T F}(\text { state }) d m
\end{aligned}
$$

Several simplifications are adopted in the expression of the conservation of energy. Firstly the HTF is assumed to be incompressible and the thermal expansion of the HTF volume is assumed to be negligible. The in- and outgoing HTF mass flow rate is thus equal and given by $\dot{m}$. Furthermore, the kinetic and potential energy change of the LTES heat exchanger is neglected as well as the kinetic and potential energy change between in- and outlet of the HTF. The resulting first law of thermodynamics is expressed as

Equation 2 with $\dot{Q}_{\text {loss }}$ the heat losses over the boundary of the LTES heat exchanger and $h_{\text {out }}$ and $h_{\text {in }}$ the specific enthalpy at respectively the in- and outlet of the control volume. Note that all the terms in Equation 2 are functions of time. 


$$
\frac{d U}{d t}=\dot{Q}_{\text {loss }}+\dot{m}\left(h_{\text {out }}-h_{\text {in }}\right)
$$

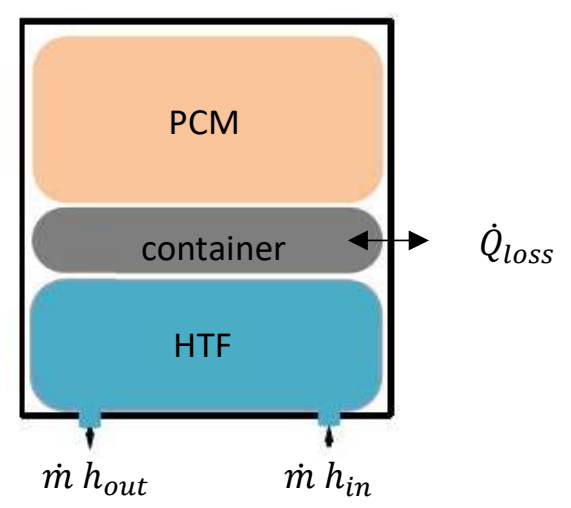

Figure 2: Schematic representation of control volume and constituting materials in a LTES heat exchanger.

The goal of the model is to predict the outlet state for a given HTF mass flow rate and state at the inlet. Directly correlating the outlet state is however not possible since only limiting cases are known for the outlet state. For example when cooling a LTES heat exchanger with a constant HTF inlet state, the outlet temperature will not increase above the initial state nor decrease below the inlet temperature.

Instead of correlating the outlet state directly, the net efflux of energy $\dot{Q}_{f}$ can be correlated which relates inlet and outlet state. The net efflux of energy is the energy transfer associated with the mass flow of HTF (Equation 3).

$$
\dot{Q}_{f}=\dot{m}\left(h_{\text {out }}-h_{\text {in }}\right)
$$

The heat losses are composed of two parts. Firstly, there is heat transfer between the surface of the LTES heat exchanger and the ambient. This heat transfer can be minimized by applying sufficient thermal insulation. Secondly, the heat transfer required to heat (or cool) the insulation itself. This part can be reduced by choosing insulation materials with a low density and specific heat capacity. Since both parts of the heat losses can be sufficiently decreased by applying insulation, the heat losses are assumed negligible.

Using the conservation of energy expressed by Equation 2 requires determining the rate of change of the internal energy of the battery. The rate of change can be determined by measuring the local state of the LTES heat exchanger and numerically differentiating the result. Measuring the local state of an LTES heat exchanger is a similar problem to determining the state of charge of the LTES heat exchanger.

The problem of state of charge measurement is well studied in literature [48], however practical considerations limit the applicability of most solutions. For example, to measure the sensible stored heat a grid of temperature measurements can be acquired throughout the LTES heat exchanger. However, it is often not possible to obtain enough temperature measurements inside a LTES heat exchanger. Since the method should be applicable to any LTES heat exchanger, it should not depend on a local state measurement. 
The internal energy at the start and end of a charging cycle can be known by considering a cycle between two known states. For example, the initial state is known when initializing the LTES heat exchanger at a constant uniform temperature outside of the PCM's two-phase zone. If the charging cycle is than performed with a constant HTF inlet temperature the eventual temperature of the battery will be equal to this HTF inlet temperature. For such a cycle, the stored energy at the end of the cycle $t_{\text {end }}$ is given by Equation 4.

$$
\int_{t_{\text {start }}}^{t_{\text {end }}} U(\text { state }(t)) d t=U\left(\text { state }_{\text {end }}\right)-U\left(\text { state }_{\text {start }}\right)=\Delta U
$$

The stored internal energy at any time during the charging cycle $J(t)$ can be written as Equation 5 with $\alpha(t)$ the energy fraction as a function of time. This energy fraction $\alpha(t)$ is a continuously increasing function between 0 and 1 , it is thus a cumulative distribution function describing the stored energy. However, since there is no measurement of the local state, there is not yet a method to actually measure the energy fraction function.

$$
J(t)=\int_{t_{\text {start }}}^{t} d U=\alpha(t) \Delta U
$$

The efflux of energy can also be integrated in time to return the integrated efflux of energy $Q_{f}$ which results in Equation 6. In contrast to the local state, the integrated efflux of energy can easily be determined from measurements. The measurements required to estimate the efflux of energy are external to the LTES heat exchanger. Therefore obtaining the measurements requires adapting the in- and outlet connection of the heat exchanger rather than adapting the heat exchanger itself as is required for internal state measurements.

$$
Q_{f}(t)=\int_{t_{\text {start }}}^{t} \dot{m}\left(h_{\text {out }}-h_{\text {in }}\right) d t
$$

Equation 2 can now be integrated in time which results in Equation 7. The integrated efflux of energy $Q_{f}(t)$ can be determined from external measurements while the total stored energy $\Delta U$ is known for the chosen charging cycle. Equation 7 thus allows to determine the energy fraction cumulative distribution function $\alpha(t)$.

$$
\alpha(t) \Delta U=Q_{f}(t)
$$

By correlating the energy fraction function $\alpha(t)$, the outlet state of the LTES heat exchanger can be determined. The partial distribution function associated with the cumulative distribution function is determined by differentiating the energy fraction function $\alpha(t)$ with respect to time. Equation 2 can thus be rewritten as Equation 8 which results in a relation between the outlet of the HTF as a function of the energy fraction function and the inlet conditions.

$$
\frac{d \alpha}{d t} \Delta U=\dot{m}\left(h_{\text {out }}-h_{\text {in }}\right)
$$

Mathematically there is no difference between correlating the energy fraction function $\alpha(t)$ or the time derivative of the function $\frac{d \alpha}{d t}$ since these functions are linked as a cumulative and partial distribution function. However, in a practical case the functions will be determined based on experimental measurements. Experimental measurements are always subject to measurement errors. Taking the difference of two measurements increases the variance of the noise while numerical integration reduces 
measurement noise. Therefore the measured cumulative distribution function is correlated rather than the partial distribution function.

The problem of predicting the outlet state of the HTF is translated to correlating the energy fraction $\alpha(t)$ as a function of time, the initial and inlet conditions. To correlate $\alpha(t)$, two issues need to be resolved. Firstly, a parametrized function for $\alpha(t)$ as a function of the inlet conditions and initial state needs to be determined. Secondly, an objective function needs to be defined to be able to fit the parameters to the measured energy fraction.

Finding a parametrized function for $\alpha(t)$ is difficult since throughout a charging cycle different transfer processes will be dominant [9]. The initial phase for example is dominated by the mass conservation of the HTF, which is followed by sensible heat, latent heat and finally sensible heat. Since the thermal battery can be locally in different phases along the flow length of the HTF, the transition between the phases is not clearly definable.

An objective function can be defined by integrating the absolute difference between the correlated and measured outlet state. The parameters can then be chosen to minimize the absolute integrated difference, however this is a complex optimization problem and will favor accuracy in the initial phase with large efflux of energy.

The fitting problem can be split in a series of fitting problems by fitting the charging time as a function of the energy fraction instead of the energy fraction as a function of time. Martinelli et al. [52] and Kuboth et al. [53] defined the charging time for an energy fraction $\alpha_{i}$ by Equation 9 . Both authors chose a value of $\alpha_{i}$ close to 1 to estimate the total charging time. In the present context, a series of $\alpha_{i}$ values are chosen between 0 and 1 which results in a series of charging time measurements $t_{c}\left(\alpha_{i}\right)$. The problem of fitting the energy fraction function $\alpha(t)$, is thus split into fitting a correlation for the charging time for each energy fraction level $t_{c}\left(\alpha_{i}\right)$.

$$
t_{c}\left(\alpha_{i}\right) \text { for which } Q_{f}(t)=\alpha_{i} \max _{t} Q_{f}(t)
$$

Note that it is not possible to reverse this process by picking times at which the energy fraction is determined since the charging time is defined in a left bounded interval rather than the bounded interval in which the energy fraction is defined.

The prediction of the outlet state thus comes down to finding a function for the charging time $f$ and determining the parameters $p$ of the function for several energy fractions $\alpha_{i}$ by comparing the measured charging time (Equation 9) with the predicted charging time (Equation 10).

$$
t_{c}\left(\alpha_{i}\right)=\boldsymbol{f}\left(\dot{m} ; h_{i n} ; p\left(\alpha_{i}\right)\right)
$$

The mean efflux of energy $\overline{\dot{Q}}_{f}^{\alpha_{1}, \alpha_{2}}$ between two energy fractions $\alpha_{1}$ and $\alpha_{2}$ can be determined as Equation 11.

$$
\overline{\dot{Q}}_{f}^{\alpha_{1}, \alpha_{2}}=\frac{\alpha_{1}-\alpha_{2}}{\boldsymbol{f}\left(\dot{m} ; h_{i n} ; p\left(\alpha_{2}\right)\right)-\boldsymbol{f}\left(\dot{m} ; h_{i n} ; p\left(\alpha_{1}\right)\right)} \Delta U
$$

The mean outlet state between energy fractions $\alpha_{1}$ and $\alpha_{2}$ can now be determined as Equation 12 where $h_{\text {in }}$ and $\dot{m}$ are the measured inlet state and mass flow rate evaluated at the average time between $t_{c}\left(\alpha_{1}\right)$ and $t_{c}\left(\alpha_{2}\right)$. 


$$
\bar{h}_{\text {out }}^{\alpha_{1}, \alpha_{2}}=h_{\text {in }}\left(t_{m}\right)-\frac{\overline{\dot{Q}}_{f}^{\alpha_{1}, \alpha_{2}}}{\dot{m}\left(t_{m}^{\alpha_{1}, \alpha_{2}}\right)} \text { with } t_{m}^{\alpha_{1}, \alpha_{2}}=\frac{\boldsymbol{f}\left(\dot{m} ; h_{i n} ; p\left(\alpha_{2}\right)\right)+\boldsymbol{f}\left(\dot{m} ; h_{\text {in }} ; p\left(\alpha_{1}\right)\right)}{2}
$$

Equations 4, 10, 11 and 12 constitute the charging time energy fraction model for predicting the outlet state of LTES heat exchangers.

The remaining question is determining the charging time function $\boldsymbol{f}\left(\dot{m} ; h_{i n} ; p\left(\alpha_{i}\right)\right)$. Beyne et al. [47] extended an analytical solution by Bauer et al. [63] to propose a general correlation for the total charging time. The general correlation links the charging time as a function of $\Delta T$ which is the temperature difference between the HTF inlet and the peak PCM phase change temperature (Equation 13). The correlation worked sufficiently for several data sets in literature however the data was too limited to make a general conclusion.

$$
t_{c}=\frac{\text { Slope }}{\Delta T}+\text { Intercept }
$$

Since no general correlation is available, the charging time correlation has to be developed for each specific LTES heat exchanger separately. To illustrate this process of fitting the charging time energy fraction model, the remainder of the paper will discuss a specific LTES heat exchanger.

The procedure for calibrating a model using the charging time energy fraction method is shown in Figure 3. The blue rectangle represents measurements and calculations which are done for a set of experiments with an inlet mass flow rate level $\dot{m}_{\text {level }}$ and enthalpy level $h_{\text {level }}$. For each experiment, the efflux of energy $\dot{Q}_{f}(t)$, integrated efflux of energy $Q_{f}(t)$ and energy fraction $\alpha(t)$ are determined as a function of time. The charging time $t_{c}\left(\alpha_{i}\right)$ is than determined for a chosen set of energy fractions $\alpha$. The set of charging times is correlated by using fitting a charging time correlation $f\left(\dot{m}_{\text {level }} ; h_{\text {level }} ; p\right)$ to the charging time determined for all experiments. The result of the fitting are the correlation parameters $p\left(\alpha_{i}\right)$ for all energy fractions $\alpha_{i}$ in the base set $\alpha$.

The resulting model consists of three components: the charging time correlation, the set of correlation parameters and the mass and properties of each constituting material. Figure 4 shows a flow chart of how to use such a model to predict the outlet state for given inlet and initial conditions. The inlet conditions are combined with the charging time correlation and correlation parameters to determine the charging time for all energy fractions in the base set. The total stored energy is determined from the mass and properties of the constituent materials and the initial and final conditions. The total stored energy is combined with the charging time to estimate the stored energy which is differentiated to determine the efflux of energy. Finally the outlet state is determined from Equation 12.

In both Figure 3 and Figure 4, the inlet conditions are defined as functions of time $\dot{m}(t)$ and $h_{\text {in }}(t)$ while the charging time correlation is based on constant inlet levels $\dot{m}_{\text {level }}$ and $h_{\text {level }}$. The charging time energy fraction method thus requires inlet conditions which are relatively constant around fixed levels. How much the inlet conditions can vary from constant levels can only be resolved by calibrating and validating a model for a real LTES heat exchanger. 


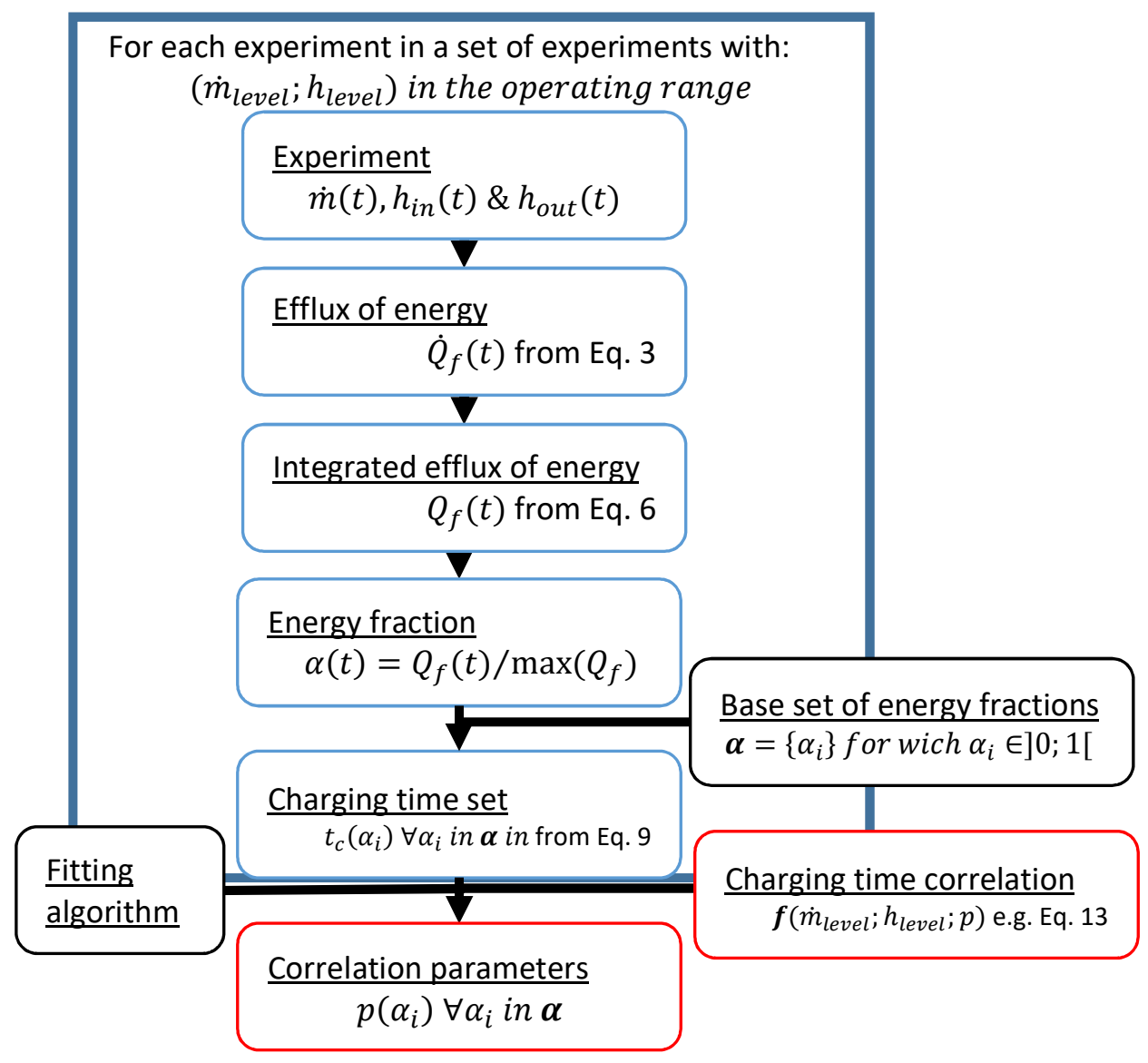

Figure 3: Flowchart representation of the charging time energy fraction method to calibrate a model from a set of experiments. The model is determined by the charging time correlation, correlation parameters for a set of energy fractions and the material properties. 


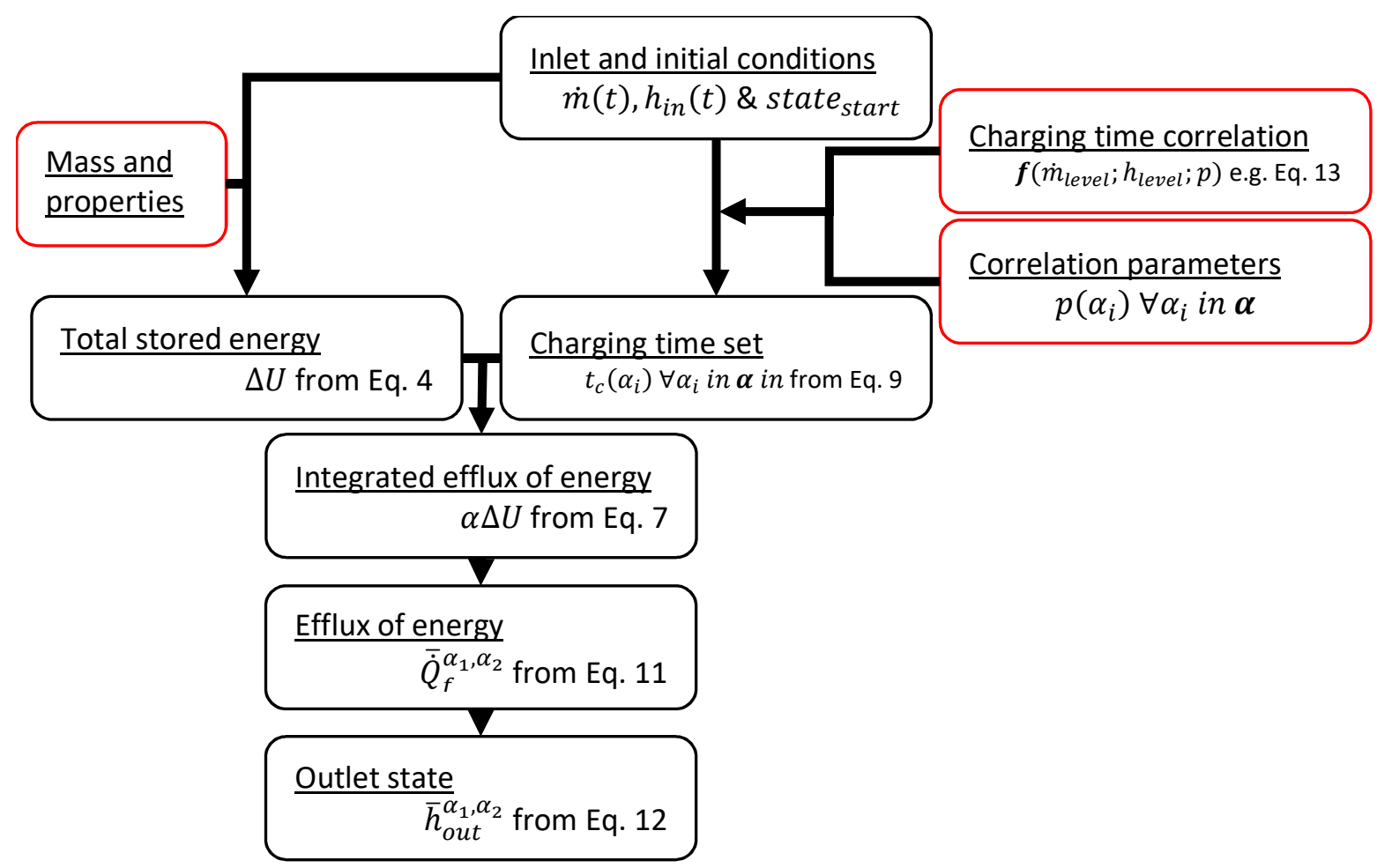

Figure 4: Flowchart representation of predicting the outlet state for known inlet and initial conditions based on a model fitted using the charging time energy fraction method. The red rectangles are the parameters defining the model.

\section{Latent thermal energy storage heat exchanger}

The LTES heat exchanger used to illustrate the charging time energy fraction model is a thermal battery for cold chain transport which was previously described by Beyne et al. [47]. For all details on the geometry, the reader is referred to this publication. The present section summarizes the construction of the thermal battery and properties required to fit the charging time energy fraction model.

Figure 5 shows a photograph of the thermal battery. The thermal battery is a modular design based on an extruded aluminum profile. The cross section of the extruded profile is shown on Figure 6 . It contains seven channels which are welded shut after placement of metal foam inserts. These channels are filled with a PCM and metal foam. Between the PCM channels, there are six channels to allow the heat transfer fluid (HTF) to flow through the profile. At the top, there is an air channel which allows connecting with the bottom of another profile. 


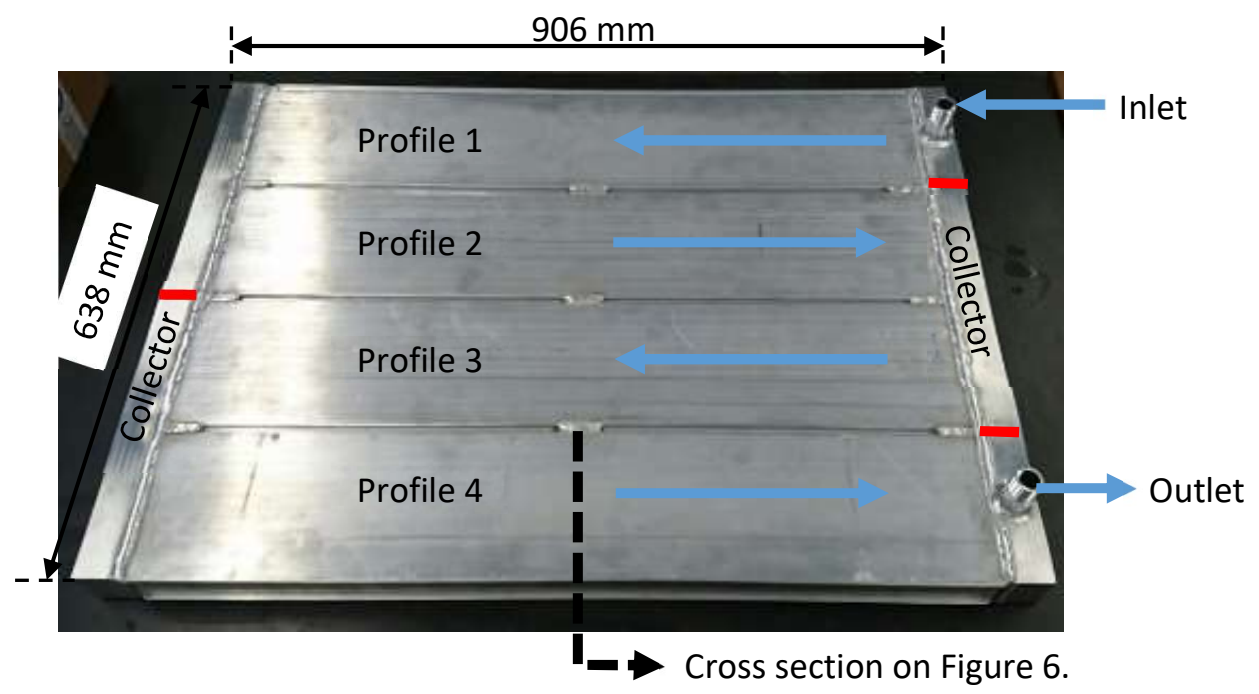

Figure 5: LTES heat exchanger studied in this article.

The extruded profile is cut into four pieces and connected using the air channel. Two collectors are connected to the top and bottom of the four profiles. The collectors are split on the red lines shown on Figure 5. Finally, an inlet and outlet nipple are welded on the top collector to connect HTF hoses. The resulting flow of HTF is aligned according to the blue lines on Figure 5.

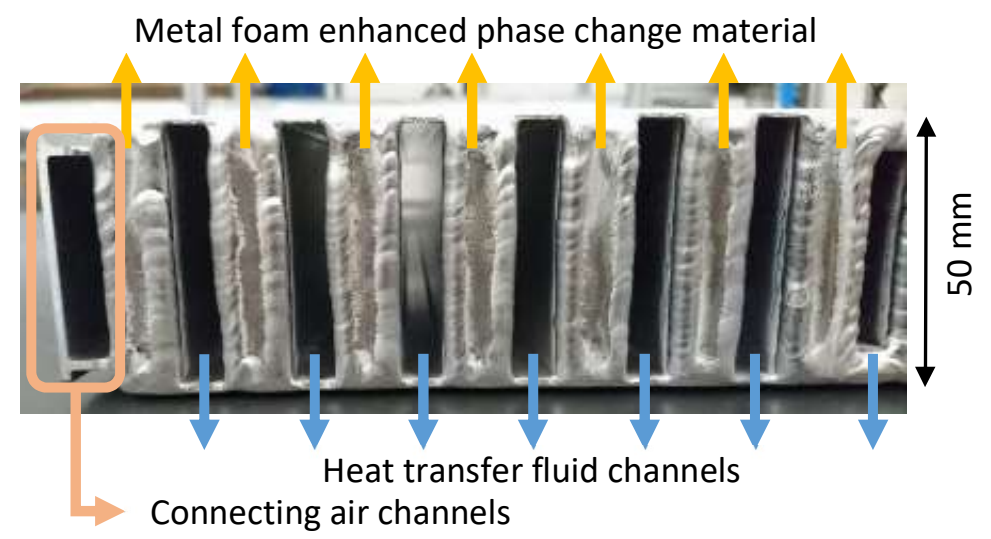

Figure 6: Cross section of profile with HTF channels, PCM channels and connecting air channels.

The main geometric properties of the LTES heat exchanger are summarized in Table 1.

\begin{tabular}{lll|lll} 
Property & Value & Units & Property & Value & Units \\
\hline Profile length & 806 & $\mathrm{~mm}$ & Height A-B channels & 50 & $\mathrm{~mm}$ \\
Profile height & 54 & $\mathrm{~mm}$ & Collector width & 638 & $\mathrm{~mm}$ \\
Extrusion wall thickness & 2 & $\mathrm{~mm}$ & Collector wall thickness & 3 & $\mathrm{~mm}$ \\
Width PCM-foam channels & 10 & $\mathrm{~mm}$ & Collector depth & 50 & $\mathrm{~mm}$ \\
Width HTF channels & 8 & $\mathrm{~mm}$ & Porosity metal foam & 0.96 & -
\end{tabular}

Table 1: Geometric parameters of the LTES heat exchanger.

The thermal battery is charged by a flow of Temper 30 [64] with an inlet temperature between $0{ }^{\circ} \mathrm{C}$ and $15^{\circ} \mathrm{C}$ and a mass flow rate between $0.25 \mathrm{~kg} / \mathrm{s}$ and $1.0 \mathrm{~kg} / \mathrm{s}$. To supply the cold flow of HTF, a large vessel 
of Temper 30 is chilled prior to starting the experiment. The chiller is turned off once the HTF in the vessel is at the set point temperature. A frequency controlled pump is used to generate the flow of HTF through the thermal battery.

The application for the LTES heat exchanger is cold storage for cold chain transport between temperature limits of $2-8{ }^{\circ} \mathrm{C}$. The PCM thus needs to have a phase change between $2-8{ }^{\circ} \mathrm{C}$. Therefore, the paraffin RT5HC from the company Rubitherm is chosen [14]. This paraffin is both compatible with the aluminum material of the LTES heat exchanger, is commercially available and has a narrow phase change range in between $2-8^{\circ} \mathrm{C}$.

The chosen PCM however has a relatively low thermal conductivity of about $0.2 \mathrm{~W} / \mathrm{mK}$. As discussed by Beyne et al. [47], the low thermal conductivity increases the operational cost of the system by increasing the charging time. Metal foam has been shown to be an effective enhancement method especially for solidification in phase change materials [65-67]. The present LTES heat exchanger uses an aluminum metal foam with a porosity of 0.96 and a pore density of 10 pores per inch. For an analysis of the impact of the metal foam on the performance of the heat exchanger, the reader is referred too Beyne et al. [47].

The experimental procedure results in a mass flow rate and inlet temperature which deviate from the step change used to fit the charging time energy fraction model. The pump has a startup time of about 15 seconds before it reaches a steady value. The inlet temperature also has a transient at the start of the experiments since the HTF in the hoses has to be replaced. Once the set point temperature has been reached, the inlet temperature increases slightly due to mixing in the HTF vessel. The data reduction and model fitting will have to account for this deviation.

To fit the model, the HTF mass flow rate and temperature at inlet and outlet need to be measured. To measure the temperature, a measurement section is included at the end of the connecting hoses. In each of these measurement sections, two K-type thermocouples are submerged in the HTF flow. The thermocouples are referenced using a Pt100 and calibrated to an uncertainty of $\pm 0.15^{\circ} \mathrm{C}$. The mass flow rate is measured by a Krohne Optimass $1400 \mathrm{C} \mathrm{S} 25$ with an accuracy of $\pm 0.15 \%$ of the measured mass flow rate plus a minimum error of $0.00075 \mathrm{~kg} / \mathrm{s}$. All five measurements are acquired by a Keithley 2700 multiplexer through Labview with a maximum sampling time of 5 seconds.

The energy stored in the LTES heat exchanger $\Delta U$ is the sum of the internal energy change of the HTF, container material and PCM for a temperature difference between the initial temperature $T_{\text {start }}$ and the final temperature $T_{\text {end }}$. In all experiments, the initial temperature $T_{\text {start }}$ is at room temperature and thus above the liquidus temperature of the PCM while the final temperature is between 0 and $-15^{\circ} \mathrm{C}$ and thus below the solidus temperature. The PCM is thus completely liquid at the start of the experiment and completely solid at the end. As a result the energy stored in the LTES heat exchanger is given by Equation 14.

$$
\begin{aligned}
\Delta U\left(T_{\text {start }}, T_{\text {end }}\right) & =\rho_{\text {HTF }} V_{H T F}\left(u_{H T F}\left(T_{\text {end }}\right)-u_{\text {HTF }}\left(T_{\text {start }}\right)\right) \\
& +m_{\text {alu }} c_{\text {alu }}\left(T_{\text {end }}-T_{\text {start }}\right) \\
& +m_{P C M}\left[c_{P C M}\left(T_{\text {end }}-T_{\text {start }}\right)+h_{\text {lat }}\right]
\end{aligned}
$$

The relevant properties of the PCM, HTF and aluminum are summarized in Table 2. The PCM properties are supplied by the manufacturer [14]. The manufacturer of Temper 30 supplies tabulated properties. The tabulated specific heat capacity $c_{\text {HFF }}$ are fitted by a polynomial in Equation 15 . The order of the polynomial 
is chosen to result in a fitting error on the same order of magnitude as the measurement error on the reported properties. The HTF fluid is modeled as an incompressible fluid which allows determining the internal energy of the HTF as Equation 16.

\begin{tabular}{lll|lll|lll}
\multicolumn{3}{c|}{ PCM } & \multicolumn{3}{c|}{ HTF } & \multicolumn{3}{c}{ Aluminum } \\
\hline$m_{P C M}$ & 8.074 & $\mathrm{~kg}$ & $V_{\text {HTF }}$ & 10.95 & $\mathrm{I}$ & $m_{\text {metal }}$ & 20.97 & $\mathrm{~kg}$ \\
$C_{P C M}$ & 2 & $\mathrm{~kJ} / \mathrm{kgK}$ & $\rho_{\text {HTF }}$ & 1184 & $\mathrm{~kg} / \mathrm{m}^{3}$ & $C_{\text {metal }}$ & 877 & $\mathrm{~J} / \mathrm{kgK}$ \\
$h_{\text {lat }}$ & 220 & $\mathrm{~kJ} / \mathrm{kg}$ & $U_{\text {HTF }}$ & Eq. 15 & $\mathrm{~J} / \mathrm{kg}$ & & & \\
$T_{s}$ & 4 & ${ }^{\circ} \mathrm{C}$ & $C_{\text {HF }}$ & Eq. 16 & $\mathrm{~J} / \mathrm{kgK}$ & & & \\
$T_{l}$ & 6 & ${ }^{\circ} \mathrm{C}$ & & & & & &
\end{tabular}

Table 2: Relevant properties of the PCM, HTF and container for determining the charging time energy fraction model.

$$
\begin{gathered}
c_{H T F}=-2.8610^{-5} T^{2}+1.8610^{-2} T+1.2310^{-1} \\
u_{H T F}=-2.8610^{-5} \frac{T^{3}}{3}+1.8610^{-2} \frac{T^{2}}{2}+1.2310^{-1} T
\end{gathered}
$$

Equation 12 determines the outlet enthalpy as a function of the inlet enthalpy and the predictions of the charging time energy fraction model. An enthalpy difference between two states for an incompressible fluid is the sum of the internal energy difference and the specific volume times the pressure difference. In the present case, the contribution of the pressure difference can be neglected. By furthermore assuming a constant specific heat capacity between inlet and outlet temperature, Equation 12 is rewritten as Equation 17 which determines the outlet temperature $\bar{T}_{\text {out }}^{\alpha_{1}, \alpha_{2}}$.

$$
\bar{T}_{\text {out }}^{\alpha_{1}, \alpha_{2}}=T_{\text {in }}\left(t_{m}\right)-\frac{\overline{\dot{Q}}_{f}^{\alpha_{1}, \alpha_{2}}}{\dot{m}\left(t_{m}\right) c_{H T F}\left(T_{i n}\left(t_{m}\right)\right)} \text { with } t_{m}=\frac{\boldsymbol{f}\left(\dot{m} ; T_{i n} ; p\left(\alpha_{2}\right)\right)+\boldsymbol{f}\left(\dot{m} ; T_{i n} ; p\left(\alpha_{1}\right)\right)}{2}
$$

\section{Results and discussion}

\subsection{Model calibration}

A total of 28 experiments are performed with mass flow rates between $0.25 \mathrm{~kg} / \mathrm{s}$ and $1 \mathrm{~kg} / \mathrm{s}$ with inlet temperatures between $-15{ }^{\circ} \mathrm{C}$ and $0^{\circ} \mathrm{C}$. In each experiment the battery is initially at room temperature and charged by applying a cold HTF flow. The mass flow rate is varied in four levels: $0.25 \mathrm{~kg} / \mathrm{s}, 0.5 \mathrm{~kg} / \mathrm{s}$, $0.75 \mathrm{~kg} / \mathrm{s}$ and $1.0 \mathrm{~kg} / \mathrm{s}$.

\subsubsection{Charging time measurement}

To fit the charging time energy fraction model, the charging time as a function of the energy fraction needs to be measured first. The charging time defined by Equation 9 is based on the integrated efflux of energy $Q_{f}(t)$ which in turn is a function of the temperature difference measured at the HTF inlet and outlet. Both the temperature measurement at inlet and outlet can suffer from an offset. The temperature sensor offset can be the result of a residual error in calibration or a different insertion depth of the thermocouple in the HTF flow. Therefore, the measurement setup determines the temperature offset rather than the LTES. 
Measuring the LTES with a different setup can thus result in differences in the charging times measured. To filter this effect, the temperature difference should be corrected for the steady-state mean temperature difference: $\Delta T_{S S}$. The correction leads to the definition of the corrected integrated efflux of energy $Q_{f, c}(t)$ (Equation 18).

$$
Q_{f, c}(t)=\int_{t_{\text {start }}}^{t} \dot{m}\left(h_{\text {out }}-h_{\text {in }}-c_{H T F} \Delta T_{S S}\right) d t
$$

The corrected integrated efflux of energy is compared to the integrated efflux of energy in Figure 7 as a function of time. The corrected integrated efflux of energy is higher than the integrated efflux of energy since at steady state, the outlet temperature is lower than the inlet temperature. For the uncorrected integrated efflux of energy, the location of the maximum is located at the charging time obtained from Equation 18 with a $\Delta T_{S S}$ of zero. The maximum of $Q_{f, c}(t)$ is located between this uncorrected maximum and the end of the experiment. The position of the maximum has no physical meaning since the uncertainty on $Q_{f, c}(t)$ results in a large uncertainty in charging time due to the flat maximum. Therefore, it is not possible to measure the charging time for an energy fraction approaching one.

The error on $Q_{f, c}(t)$ is smaller than the error on $Q_{f}(t)$. Over $90 \%$ of the error is the result of the error on the inlet and outlet temperature measurements and therefore the difference in error estimation is the result of a different treatment of the temperature sensor error. For the non-corrected integrated efflux of energy, there can still be an error in the form of an offset. Therefore, the errors on the temperature measurements at in- and outlet cannot be assumed independent. Since a possible offset error is corrected in $Q_{f, c}(t)$, the errors on the temperature measurements at the in- and outlet can be assumed independent. As explained by Taylor [68], the result of dependent errors is determined by simple addition while the sum of independent errors can be determined by the square root of the sum of the square of the errors. The cumulative result is a smaller error on $Q_{f, c}(t)$ than on $Q_{f}(t)$.

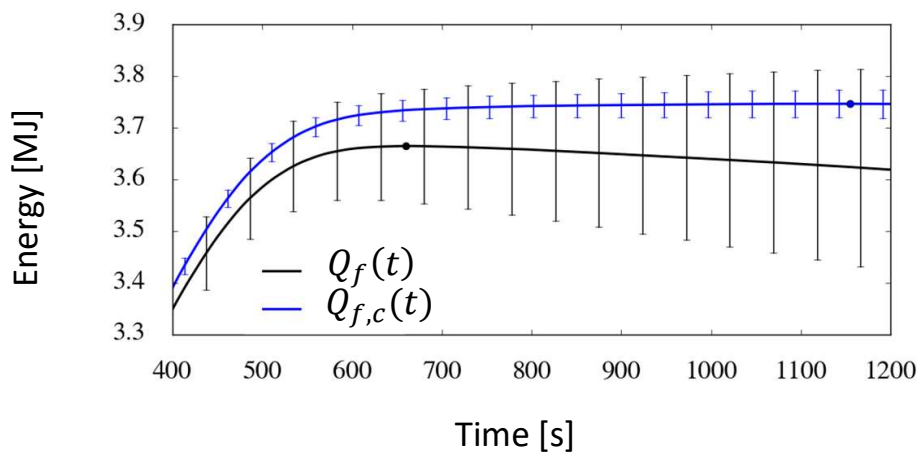

Figure 7: Comparison of integrated efflux of energy estimate $Q_{f}(t)$ and corrected integrated efflux of energy estimate as a function of time $Q_{f, c}(t)$. The maximum values are marked by dots.

The charging time $t_{c}(\alpha)$ as a function of the energy fraction $\alpha$ is shown on Figure 8 for fractions going from 0.9 to 1 .

The question rises what should be the highest energy fraction $\alpha_{i}$ chosen to correlate. As stated before, an energy fraction of one is correlated to the end of the data acquisition rather than to the end of the 
charging. However, choosing a very low fraction severely underestimates total charging time. The solution to this question is found in the error on the charging time. For higher fractions, the errors are larger and therefore the total charging time for different experiments will not be significantly different. As a result, when a too high fraction is chosen, the results will automatically become useless.

The charging time for energy fractions approaching one cannot be measured and as a result the charging time energy fraction model is not capable of predicting the outlet temperature at the end of charging. However this is not because the model is limited but rather because the temperature difference between the inlet and outlet is not measurable at the end of the cycle. As a result, the charging time energy fraction model is only incapable of predicting an insignificant temperature difference.

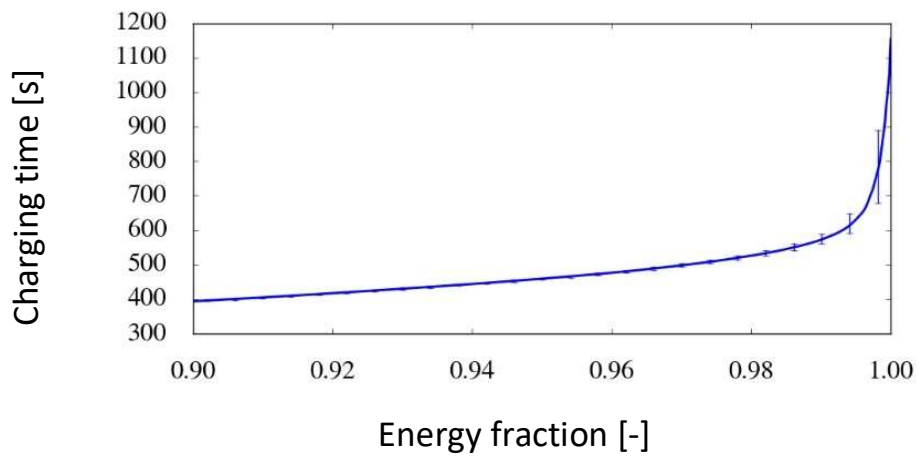

Figure 8: Charging time estimate based on the corrected integrated efflux of energy as a function of the energy fraction $\alpha$ for an experiment at $0.25 \mathrm{~kg} / \mathrm{s}$ and $-10^{\circ} \mathrm{C}$ inlet temperature.

\subsubsection{Energy balance}

The energy balance of the experiment is checked by comparing the maximum of the integrated corrected efflux of energy $\max Q_{f, c}$ to the stored energy estimate between the initial and final temperatures $\Delta U\left(T_{\text {start }}, T_{\text {end }}\right)$. The balance should close for Equation 7 to be valid and therefore for the charging time energy fraction model to be applicable.

Figure 9 shows the maximum of the integrated corrected efflux of energy ( $\max Q_{f, c}$ ) compared to the estimated stored energy $\left(\Delta U\left(T_{\text {start }}, T_{\text {end }}\right)\right)$. The error on the corrected maximum efflux of energy is the result of the error on the measured mass flow rate, inlet and outlet temperature and the HTF material properties. The error on the estimated stored energy is the result of an error in the material properties of the PCM, HTF and metal as well as the error on the initial and final temperatures.

The root mean square deviation (RMSD) between the maximum of the efflux of energy and the stored energy is $4.06 \%$ with a maximum deviation of $10.16 \%$. There is no apparent trend of the deviation as a function of the mass flow rate. 


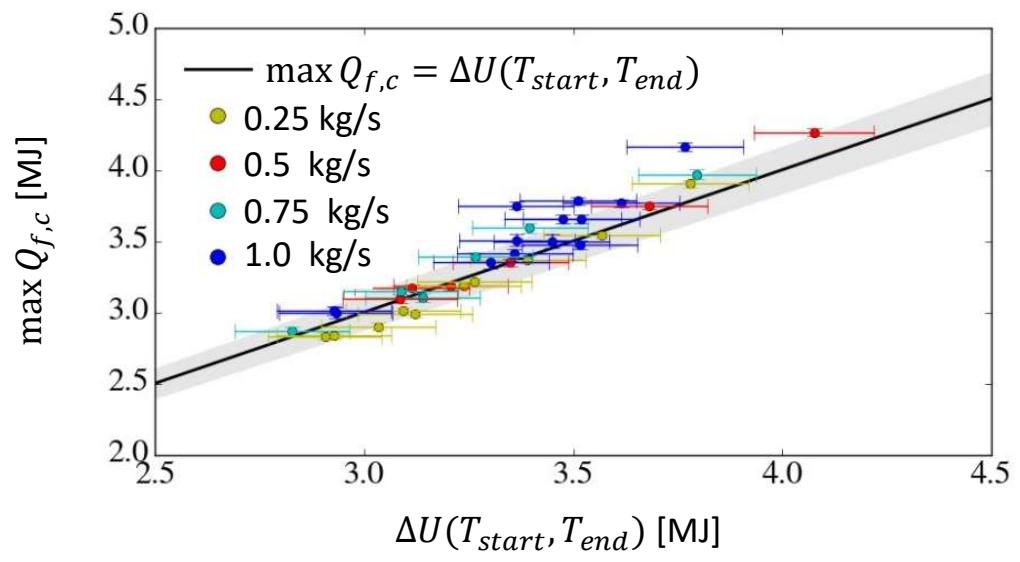

Figure 9: The maximum of the integrated efflux of energy $\left(\max Q_{f, c}\right)$ compared to the estimated stored energy $\left(\Delta U\left(T_{\text {start }}, T_{\text {end }}\right)\right)$ for the battery with foam. The gray area indicates the root mean square deviation of $4.06 \%$.

\subsubsection{Charging time correlation}

The charging time correlation (Equation 10) needs to be determined. In a previous study [47], Equation 13 was used as the base for the correlation. Both the Slope and the Intercept are functions of the HTF mass flow rate $\dot{m}$. From the reasoning of Raud et al. [46], the slope function can be determined as being linear with the inverse of the mass flow rate [47]. There is no such derivation for the intercept function. Therefore Beyne et al. [47] proposed an exponential relation between HTF mass flow rate and the intercept function which minimized the fitting error. However the initial phase of the experiment is better fitted by the inverse of the mass flow rate. The charging time correlation used to estimate the charging efflux of energy and outlet temperature is thus given by Equation 19 with $A, B, C$ and $D$ fitting coefficients.

$$
t_{c}(\alpha)=\left(A(\alpha)+\frac{B(\alpha)}{\dot{m}}\right) \frac{1}{\Delta T}+\left(C(\alpha)+\frac{D(\alpha)}{\dot{m}}\right)
$$

Equation 19 requires the step change mass flow rate level and inlet temperature. However, an experimental setup always has a transient at start up and furthermore the inlet temperature cannot be kept constant. Therefore, both the mass flow rate and inlet temperature need to be averaged in time. The correlation value of both the mass flow rate and inlet temperature is the average of the measured value after start up.

Equation 19 is fitted to the experiments for energy fractions $\alpha$ ranging from 0.01 to 0.99 . The outer limits for $\alpha$, namely 0 and 1 , do not have any predictive value since the charging time for a fraction of 0 is obviously 0 and the charging time for a fraction of 1 has too high measurement errors.

As in Beyne et al. [47], the fitting is performed in two steps. In a first step, the Slope and Intercept are determined for the four mass flow rate levels. In the second step, these slope and intercept values are fitted by the slope and intercept function proposed in Equation 19.

The deviation of the correlation from the experimental value as a function of the energy fraction is plotted in Figure 10. At the highest fractions, the root mean square (RMSD) and maximum deviation increase since the charging time measurement itself has higher errors. From an energy fraction of about 0.5 to 0.98 , the correlation achieves root mean square deviations below about $10 \%$. 
Further lowering the energy fraction leads to an increase in both root mean square and maximum deviation. The first reason for the increasing error is the nature of the chosen independent variables. One of these independent variables is the temperature difference between the average inlet temperature and the phase change temperature. This variable is correlated to the heat transfer which results in the solidification of the PCM. For lower energy fractions, the sensible heat of the HTF and sensible cooling of the battery prior to the first solidification comes into play. Therefore, only the averaged mass flow rate remains as a relevant independent variable and the $A$ and $B$ coefficients will tend to zero. The second reason for the increasing error is an increase in measurement error. In this initial phase, the increase in measurement error is not the result of low efflux of energy as it is at the final phase, but rather the sampling time of the experiment. This sampling time error is relatively larger for smaller times and therefore the measurement error increases.

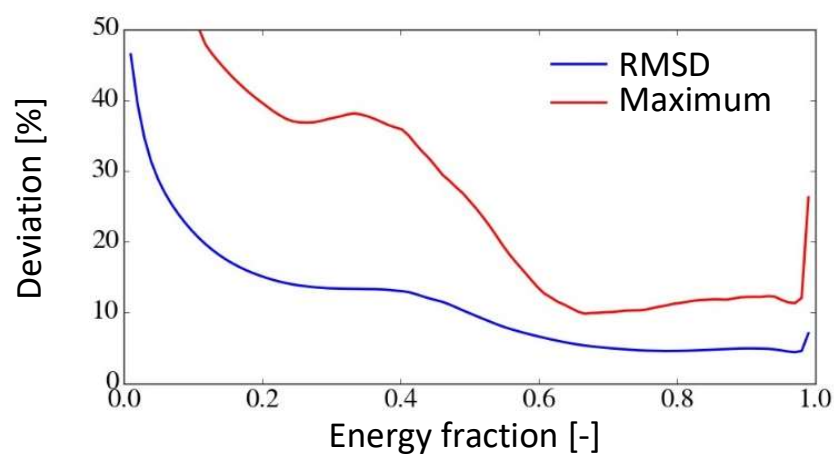

Figure 10: Root mean square and maximum deviation of the charging time correlation proposed in Equation 19 as a function of the energy fraction for the battery with foam.

The fitting coefficients as a function of the energy fraction are shown on Figure 11 for the battery with metal foam. The error bars represent the variance of the fitted coefficients.

Fitting coefficients $A$ and $B$ determine the effect of the temperature difference between the averaged inlet temperature and the phase change temperature. This temperature difference does not influence charging time for lower energy fractions since lower energy fractions are dominated by sensible cooling and HTF mass conservation. Therefore, $A$ and $B$ tend to be equal to 0 for energy fractions below 0.4 .

The Slope which is determined by coefficients $A$ and $B$ is related to the ratio of the battery energy to the average heat transfer rate. As the energy fraction increases, the battery energy which is changed increases and therefore coefficients $A$ and $B$ increase. However, the rising energy would result in a linear increase in coefficients $A$ and $B$ which is not the case. In contrast, coefficients $A$ and $B$ increase more than linearly as a function of the energy fraction.

There are two ways to understand the non-linear trend in A and B. A first explanation is a decrease in average heat transfer coefficient since for larger fractions, the solidification front reaches a further edge. The second explanation is that for higher energy fractions, the parts further along the flow length are to be solidified. Since these parts transfer heat under a lower average temperature difference, they take more time. This second explanation is consistent with both the model proposed by Raud et al. [46] and the measurements performed on the battery. 
The fitting coefficients $C$ and $D$ determine the Intercept in Equation 13. The intercept bundles the effects which are not linked to the average heat transfer coefficient. Coefficient $D$ shows a piece wise linear trend with the first part ranging from energy fraction of 0 to about 0.5 and the second part from 0.5 till the end. The final drop in the coefficient is not significant and is the result of the larger error in charging time estimate for higher energy fractions. The first linear trend is the result of two effects, firstly the mass conservation of the HTF in the battery and secondly the sensible cooling of the battery. Once the temperature drops below the solidification temperature, the stored energy is determined by the average temperature difference. As a result, the second linear trend has a decreased slope.

Coefficient $\mathrm{C}$ can be seen as a coefficient which is neither a function of mass flow rate nor of average temperature difference. However, it is fitted together with coefficient $D$ and therefore cannot be seen as a separate value. A physical interpretation of the coefficient can be found by investigating the limit of the correlation for an infinite mass flow rate. In this case the charging time is estimated as the coefficient $C$ plus the ratio of the coefficient $A$ and the average temperature difference. The ratio is the time for the battery to solidify once the phase change temperature is reached. Since for an infinite mass flow rate the temperature in the battery is uniform, the entire battery solidifies at once. The coefficient $\mathrm{C}$ is a delay to this solidification and thus represents the time required for sensible cooling of the battery. This interpretation explains why its trend is similar to the trend of coefficients $A$ and $B$.
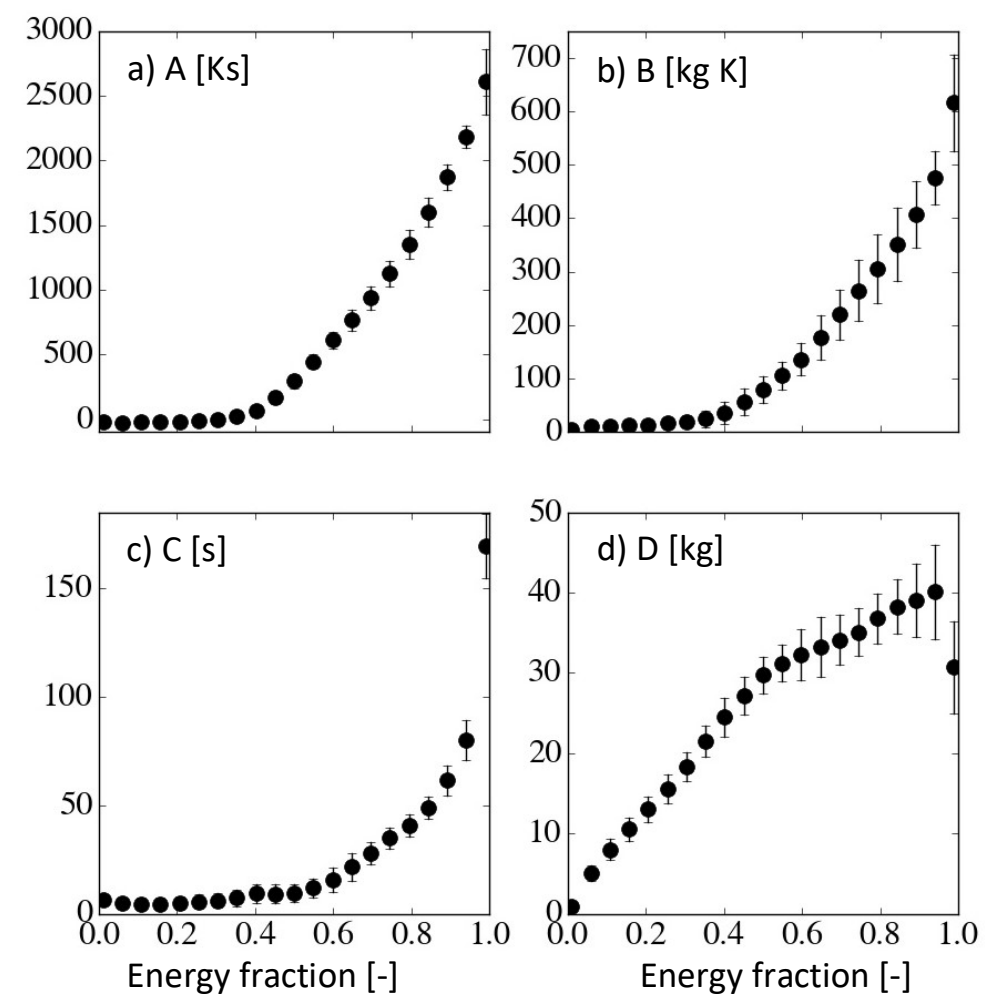

Figure 11: Fitting coefficients for the charging time correlation proposed in Equation 19 as a function of the energy fraction for the battery with foam. 


\subsection{Model evaluation}

The charging time correlation given by Equation 19 and the coefficients defined in Figure 11 are used to predict stored energy, efflux of energy and the outlet temperature as a function of time according to Equations 11 and 17. The model is constructed by estimating charging time for each energy fraction between 0.01 and 0.99 . The resulting predictions can be compared to the measured outlet temperature, efflux of energy and energy as a function of time. However, presenting the results as a function of time for all of the experiments is an extensive and mostly superfluous endeavor. Therefore, a criterion is necessary to rate and compare the fitting of the estimates to the measurements.

The criterion can be based on the temperature, efflux of energy or stored energy estimates. Efflux of energy and stored energy are estimates based on the measurements of the inlet and outlet temperature. In contrast, the outlet temperature is a direct measurement and therefore the criterion to compare is based on the outlet temperatures.

The absolute temperature difference between the measured and estimated outlet temperature is integrated over time. This integrated value is than divided by the measured charging time $t_{c}(0.975)$ to retrieve the integrated absolute temperature difference $I_{\Delta T}\left(\alpha_{j}\right)$ as Equation 20.

$$
I_{\Delta T}\left(\alpha_{j}\right)=\sum_{i=0}^{j}\left(\left|\bar{T}_{\text {out }}^{\alpha_{i+1} \alpha_{i}}-\frac{T_{\text {out }}\left(t_{c}\left(\alpha_{i+1}\right)\right)+T_{\text {out }}\left(t_{c}\left(\alpha_{i}\right)\right)}{2}\right| \frac{t_{c}\left(\alpha_{i+1}\right)-t_{c}\left(\alpha_{i}\right)}{t_{c}(0.975)}\right)
$$

The model predictions are evaluated first for the experiments used to calibrate the charging time energy fraction correlation in Section 4.2.1. In a second step, additional experiments are used to test the predictions of the model (Section 4.2.2).

\subsubsection{Calibration experiments}

The experiments can be ranked from lowest to highest value of the integrated temperature difference $I_{\Delta T}(0.99)$. This would skew the selection to cases where the initial phase is well fitted, since the largest temperature differences between HTF in- and outlet are found in the initial phase. However, the phases dominated by the heat transfer are intrinsically more interesting since it is more complex to predict. The initial phase can be excluded from the evaluation by comparing the difference in integrated absolute temperature difference between the final energy fraction and an energy fraction higher than 0 . A base energy fraction of 0.4 is chosen which excludes the initial replacement phase from the evaluation.

The experiment with the best fit is selected and the results of the stored energy, efflux of energy and temperature are shown in Figure $12 \mathrm{a}, \mathrm{b}$ and $\mathrm{c}$. The estimated integrated efflux of energy $Q_{f}$ is predicted by the correlation within the uncertainty range of the experiment. The success of the energy prediction depends on two factors. Firstly the difference between estimated stored energy $\Delta U$ and integrated efflux of energy must be as small as possible, or in other words the energy balance must be closed. In this case there is a deviation of only $3.7 \%$. Secondly, the charging time estimates need to be correct. This timing is also correct without any time shift between the signals. The estimation does not continue until the end of the experiment since the model is constructed from an energy fraction of 0.01 to 0.99 .

By differentiating the correlated energy with respect to time (Equation 11) the predicted efflux of energy $\bar{Q}_{f}^{\alpha_{1}, \alpha_{2}}$ is obtained. From 30 s onwards, the measured and predicted efflux of energy are predicted within the error margins. At the start of the experiment, there is a deviation between measured and predicted efflux of energy. 
The start of the experiment is not predicted within the error margin of the experiment. The initial charging phase is determined by the mass conservation of the HTF and later the sensible cooling of the battery. The time constant for this initial phase is much smaller than the time constant for the remainder of the charging. More exactly, for the maximum tested mass flow rate the peak efflux of energy occurs between 10 and 15 seconds after starting the experiment. The sampling time causes both an error on the exact starting time of an experiment and on the peak time. Since the sampling time of the experiments is maximum $5 \mathrm{~s}$, the initial phase is not sampled enough to accurately estimate efflux of energy and integrated efflux of energy. Since this phase is under sampled, the charging time data for lower energy fraction itself is more scattered. As shown in Figure 10, the larger scatter results in a higher correlation error.

The deviation of $42 \%$ between estimated and predicted efflux of energy results in a large deviation of 12 $\mathrm{K}$ between estimated and correlated temperature. This is not only caused by an error in the peak efflux of energy magnitude but also by the timing of the peak. The peak efflux of energy is linked to the pump start up. The early peak efflux of energy is thus attained when the mass flow rate of the pump is not yet at its final value. Therefore a small mismatch in peak timing leads to a large error on the outlet temperature.

After the peak, the temperature estimate is within error margins between $100 \mathrm{~s}$ until the end of the experiment. The deviation before about 100 seconds is the result of a time shift rather than an error in outlet temperature estimation.

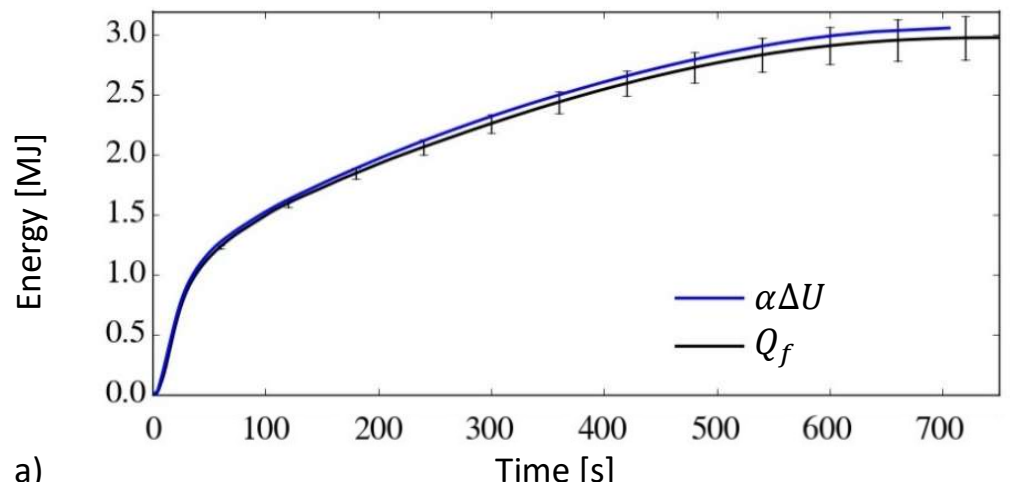




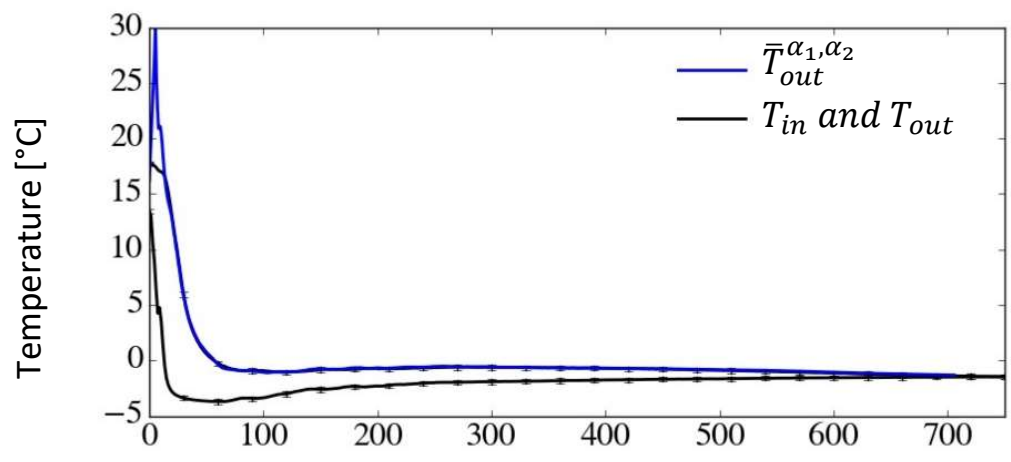

c)

Time [s]

Figure 12: The predicted energy $\alpha \Delta U$ (a), efflux of energy $\overline{\dot{Q}}_{f}^{\alpha_{1}, \alpha_{2}}$ (b) and outlet temperature $\bar{T}_{\text {out }}^{\alpha_{1}, \alpha_{2}}$ (c) compared to the estimated energy $Q_{f}(\mathrm{a})$, efflux of energy $\dot{Q}_{f}$ (b) and measured outlet temperature $T_{\text {out }}$ (c) as a function of time for the experiment with the lowest $I_{\Delta T}(0.99)-I_{\Delta T}(0.4)$ value.

Figure 13 provides a version of the inlet and outlet temperature of the experiment shown in Figure $12 \mathrm{c}$. The outlet temperature is predicted within the uncertainty range in the entire visible range. Between 100 and $300 \mathrm{~s}$ the predicted outlet temperature shows small fluctuations. These are the result of fluctuations in the inlet temperature. The measured outlet temperature does not show these jumps or shows them less pronounced since the thermal mass of the battery filters these fluctuations.

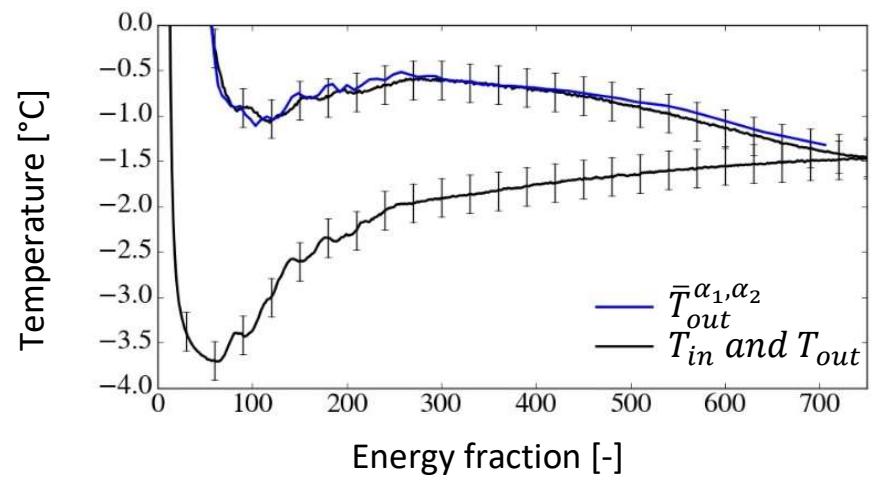

Figure 13: The predicted outlet temperature $\bar{T}_{\text {out }}^{\alpha_{1}, \alpha_{2}}$ compared to the measured outlet temperature $T_{\text {out }}$ as a function of time for the experiment with the lowest $I_{\Delta T}(0.99)-I_{\Delta T}(0.4)$ value.

The model result and measurement are compared for the experiment with the highest value of $I_{\Delta T}(0.99)-I_{\Delta T}(0.4)$ in Figure 14. As discussed for the best predicted experiment, the deviation between the estimated and correlated efflux of energy is the result of an error in the energy balance and an error in the charging time correlation. In this case, the energy balance closes within $2.1 \%$. However, the timing seems to be off with an initial delay in the correlated energy. Looking at the estimated and correlated efflux of energy, the predicted peak is delayed and lower than the estimated peak. After $100 \mathrm{~s}$ the outlet temperature is predicted within $2.9 \mathrm{~K}$, however there are non-physical fluctuations in the predictions. In the final phase, the efflux of energy is over estimated by about $0.7 \mathrm{~kW}$. The outlet temperature corresponds to the trends in predicted efflux of energy. The delayed efflux of energy peak causes a sudden 
drop in the predicted outlet temperature, in contrast to the sudden peak caused by an early predicted efflux of energy peak. The fluctuations in efflux of energy prediction after $100 \mathrm{~s}$ are transferred to the predicted output temperature. Between $250 \mathrm{~s}$ and $410 \mathrm{~s}$ the outlet temperature is predicted within the uncertainty margin, while it is over predicted by maximum $1 \mathrm{~K}$ in the final phase.

The fluctuations in predicted efflux of energy and outlet temperature are not present in the inlet temperature. They appear as a result of noise when fitting for a small step in energy fraction values.
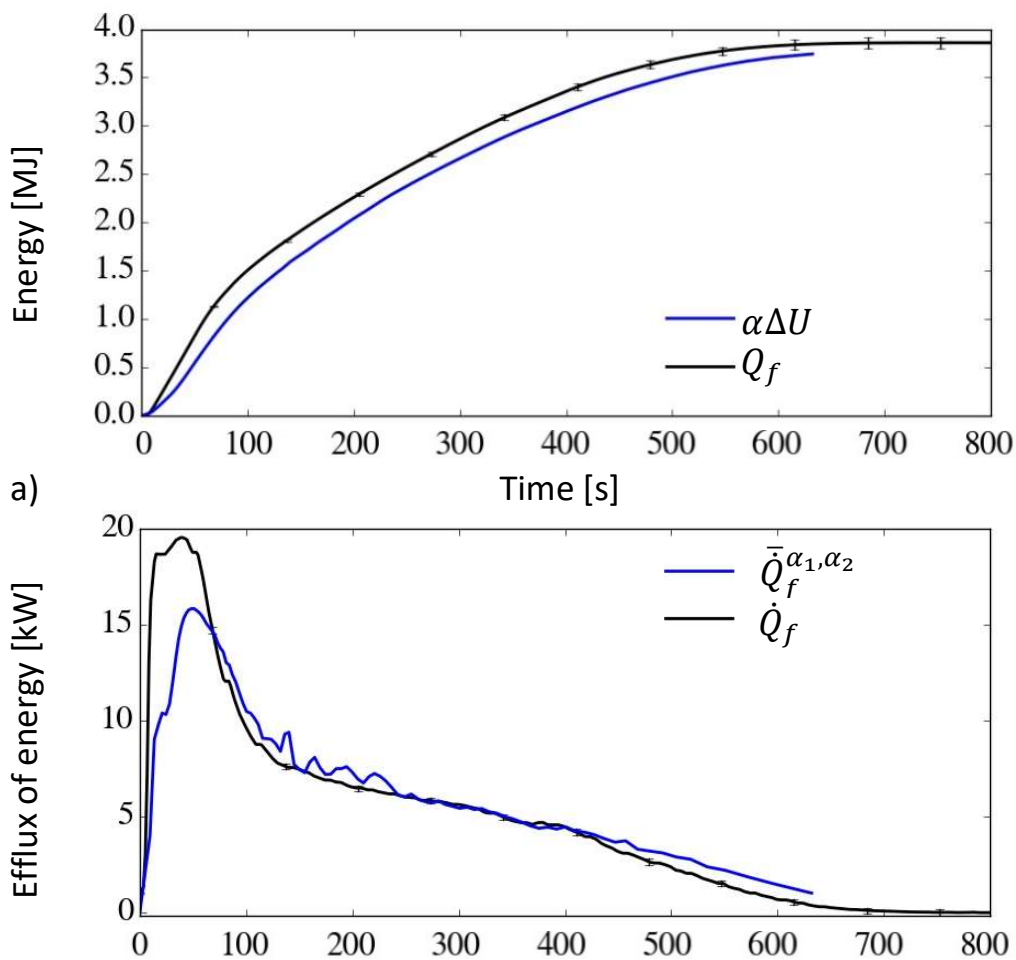

b)

Time [s]

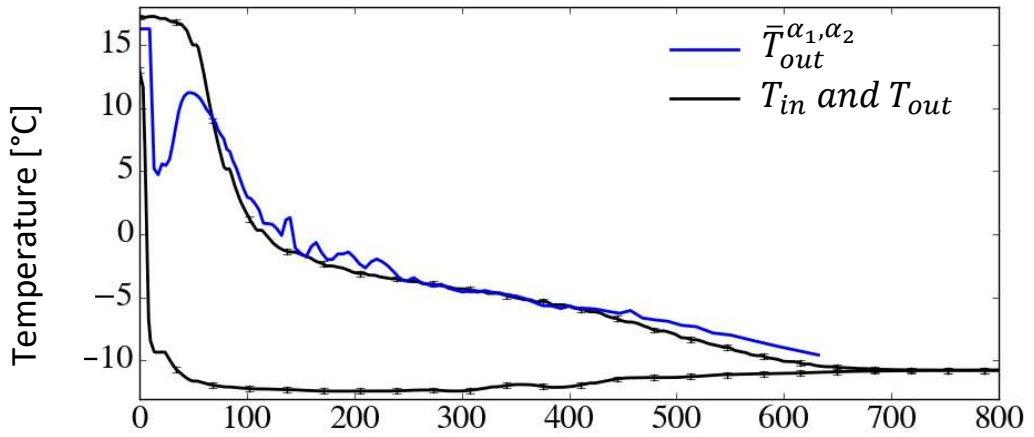

c)

Time [s]

Figure 14: The predicted energy $\alpha \Delta U$ (a), efflux of energy $\overline{\dot{Q}}_{f}^{\alpha_{1}, \alpha_{2}}$ (b) and outlet temperature $\bar{T}_{\text {out }}^{\alpha_{1}, \alpha_{2}}$ (c) compared to the estimated energy $Q_{f}$ (a), efflux of energy $\dot{Q}_{f}(\mathrm{~b})$ and measured outlet temperature $T_{\text {out }}$ (c) as a function of time for the experiment with the highest $I_{\Delta T}(0.99)-I_{\Delta T}(0.4)$ value. 
Figure 15 shows the integrated absolute temperature difference between the energy fraction 0.4 and 0.99 for all performed experiments for the battery with metal foam. The integrated difference varies between $0.42 \mathrm{~K}$ and $0.05 \mathrm{~K}$ with no obvious trend in the error as a function of the averaged mass flow rate. The model performs better on average for experiments with a higher inlet temperature. This is because a higher inlet temperature leads to a lower temperature difference between inlet and outlet and as a result a smaller error. The worst case presented in Figure 15 is an outlier with all other errors below $0.35 \mathrm{~K}$.

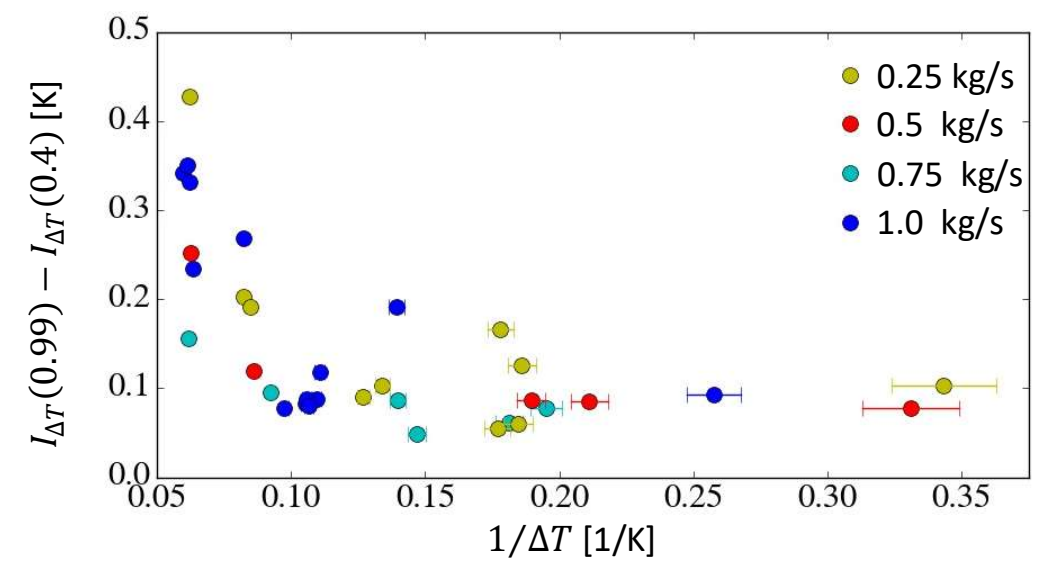

Figure 15: Integrated absolute temperature difference between the energy fraction 0.4 and 0.99 for all performed experiments for the battery with metal foam as a function of the correlation variables $1 / \Delta T$ and average mass flow rate.

\subsubsection{Validation experiments}

The experiments evaluated in Figure 15 are all carried out according to the same procedure. The vessel of $\mathrm{HTF}$ is chilled to a set temperature after which the chiller is turned off. Subsequently the pump is set to a specific pump frequency of $12.5,25,37.5$ or $50 \mathrm{~Hz}$ and turned on. The experiment is stopped once charging is complete. To validate the model, two experiments with a variation in the procedure are performed.

The first of these validation experiments applies a pump frequency of $19 \mathrm{~Hz}$ which corresponds to a mass flow rate of $0.39 \mathrm{~kg} / \mathrm{s}$. The energy, efflux of energy and temperature predictions are shown in Figure 16. The output temperature is well predicted with an integrated absolute temperature difference between the energy fraction 0.4 and 0.99 of $0.16 \mathrm{~K}$.

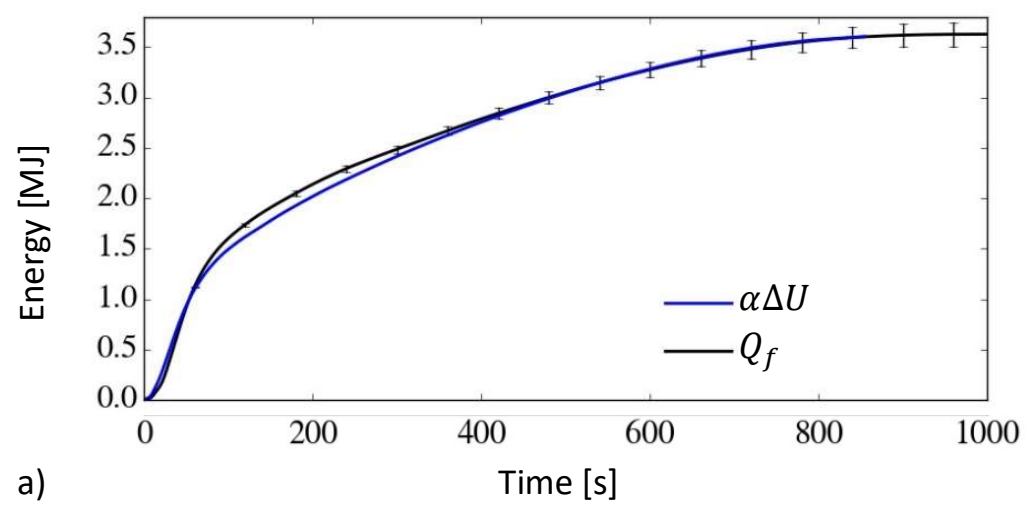



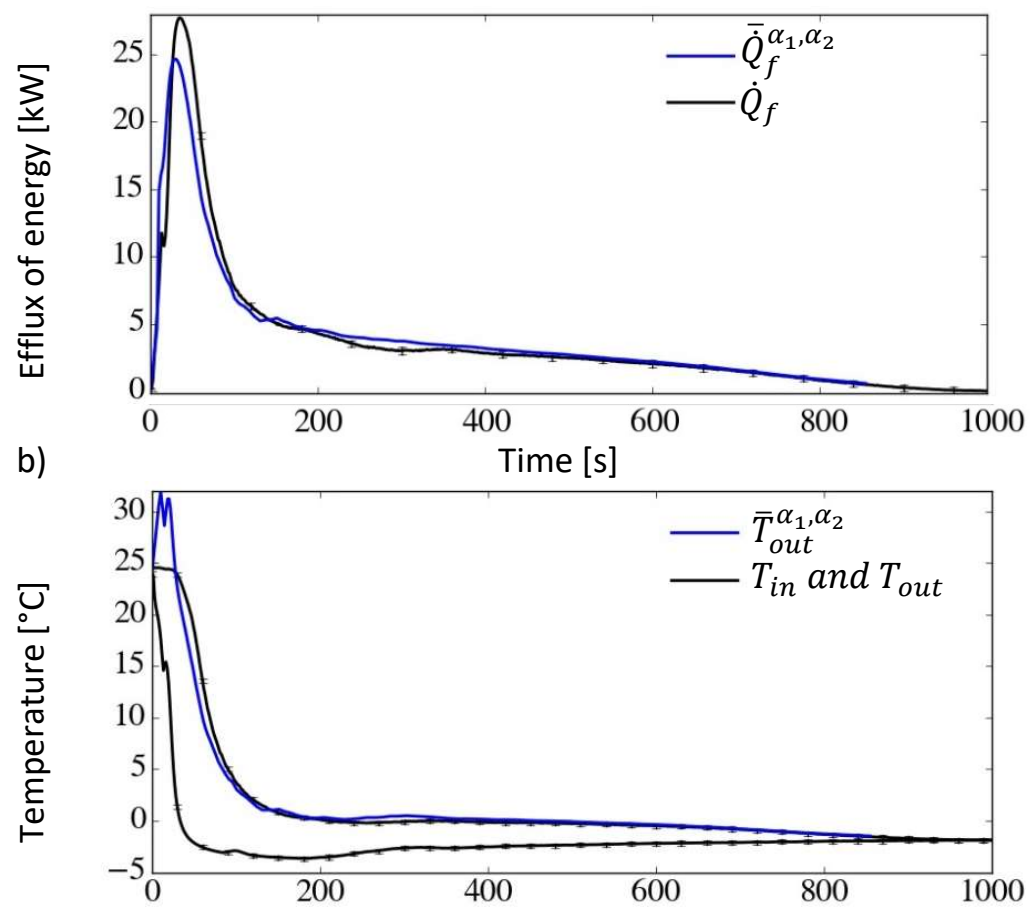

c)

Time [s]

Figure 16: The predicted energy $\alpha \Delta U$ (a), efflux of energy $\bar{Q}_{f}^{\alpha_{1}, \alpha_{2}}$ (b) and outlet temperature $\bar{T}_{\text {out }}^{\alpha_{1}, \alpha_{2}}$ (c) compared to the estimated energy $Q_{f}(\mathrm{a})$, efflux of energy $\dot{Q}_{f}$ (b) and measured outlet temperature $T_{\text {out }}$ (c) as a function of time for an experiment with an average mass flow rate of $0.39 \mathrm{~kg} / \mathrm{s}$.

In the second validation experiment, the pump is set to a frequency of $12.5 \mathrm{~Hz}$ for about 420 seconds after which it is set to $50 \mathrm{~Hz}$. To predict the experiment with a step change in mass flow rate, charging time is estimated in two parts. In the first part, the charging time is predicted using the initial average mass flow rate. During the mass flow rate step change, the charging time is estimated using the average mass flow rate after the step change. The energy fraction reached at the moment of the step change, is used as a starting point from where the curve of the second part takes over. The result is shown on Figure 17 . The efflux of energy peak (Figure $17 \mathrm{~b}$ ) resulting from the mass flow jump is not well represented with a deviation of about $5 \mathrm{~kW}$. 

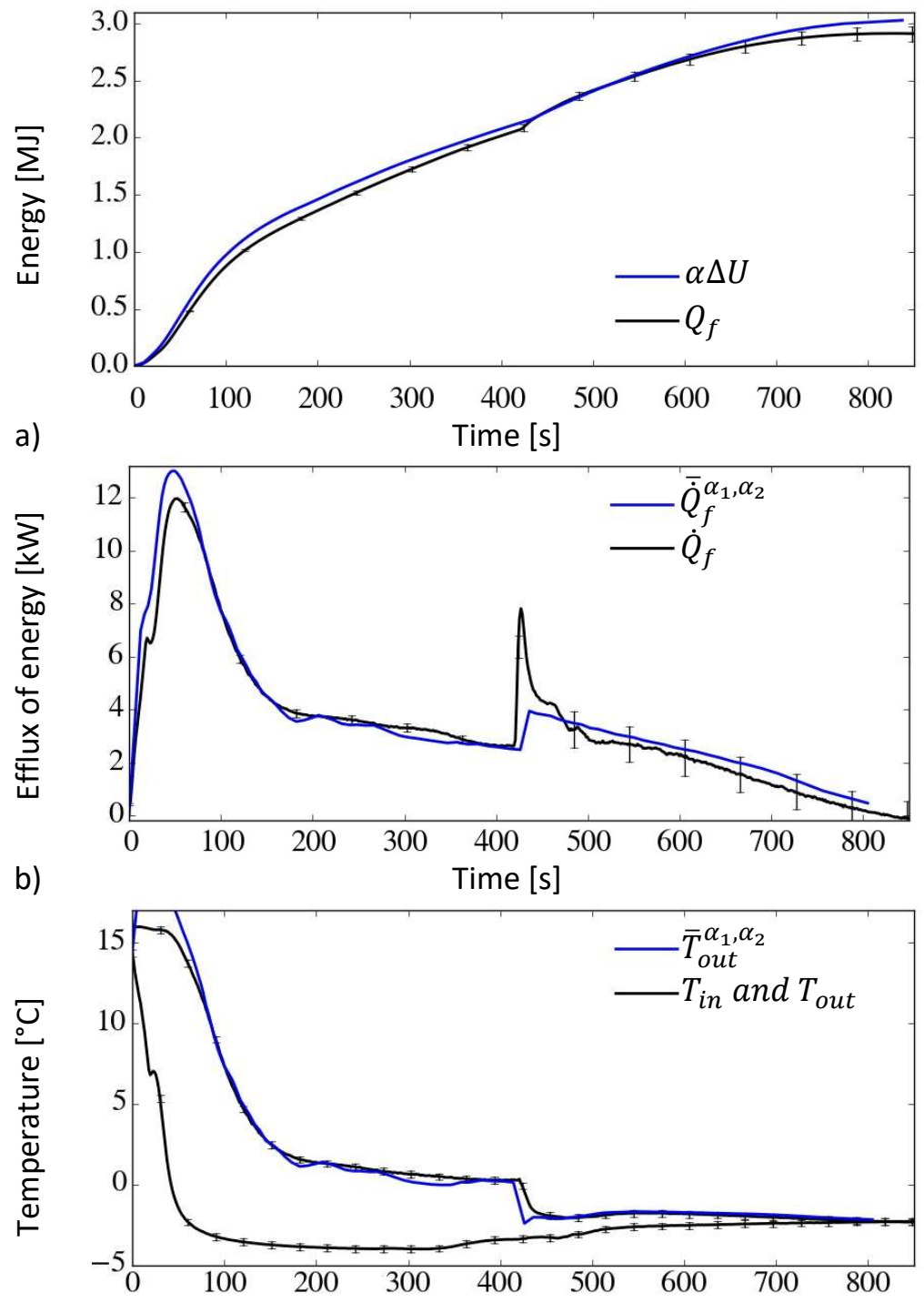

c)

Time [s]

Figure 17: The predicted energy $\alpha \Delta U$ (a), efflux of energy $\overline{\dot{Q}}_{f}^{\alpha_{1}, \alpha_{2}}$ (b) and outlet temperature $\bar{T}_{\text {out }}^{\alpha_{1}, \alpha_{2}}$ (c) compared to the estimated energy $Q_{f}(\mathrm{a})$, efflux of energy $\dot{Q}_{f}$ (b) and measured outlet temperature $T_{\text {out }}$ (c) as a function of time for an experiment with an average mass flow rate of $0.39 \mathrm{~kg} / \mathrm{s}$.

The spike in efflux of energy (Figure $17 \mathrm{~b}$ ) is a similar phenomenon as occurs at the start of the experiment. The rise in mass flow rate does not immediately result in a drop in outlet temperature since the temperature of the HTF at the outlet is determined by the heat transfer prior to the mass flow rate spike. Since the mass flow rate increases and the outlet temperature lags this mass flow rate change, there is a peak in the efflux of energy. In stored energy terms, there is a fast rise in the stored energy in the HTF in the battery due to the conservation of mass of the HTF. The charging time energy fraction model is fitted 
for a constant mass flow rate, therefore mass conservation of the HTF in the middle of the experiment is not included in the fitting coefficients.

After the peak, the efflux of energy is predicted within the error margins of the measured flow efflux of energy. As a result, the resulting temperature prediction is also within the error margin.

The two validation experiments show the approach works well to predict energy, efflux of energy and outlet temperature as a function of time for charging cycles with similar input signals as the ones for which the model is constructed.

\subsubsection{Model limitations}

The charging time energy fraction method allows to derive a predictive model for the outlet temperature of an LTES heat exchanger and thus fills the gap in literature presented in the introduction. However, the method does have limitations. These limitations can be explained by the assumptions required to derive the method.

The assumptions used when deriving the method are:

1. Negligible heat losses or gains to the ambient

2. Known masses and internal energy as a function of state of constituting materials

3. Known start and end state

4. Charging time is only dependent on mass flow rate, inlet temperature and LTES properties

5. Total charging time correlation can be expanded to lower energy fractions

6. Inlet mass flow rate and temperature are constant

The first thee assumptions are required to close the energy balance and be able to predict the total stored energy prior to an experiment. The effect of a deviation from these three assumptions must thus be viewed with respect to their impact on the prediction of the total stored energy and the energy balance.

If the heat losses or gains are not negligible, the charging time energy fraction model needs to be appended with a model for heat transfer to the ambient. In the present case study, there is no significant deviation between the integrated efflux of energy and the predicted stored energy. Since there is no significant deviation, the heat gains are negligible and a heat gains model cannot be added. Heat exchangers where the heat transfer to the ambient are not negligible will provide the base for future research on expanding the charging time energy fraction method.

The second and third assumption allow to determine the total energy stored. The masses, internal energy and the start and end state are subject to experimental errors. The start and end state in particular cannot be accurately determined based solely on measuring the HTF temperature at the in- and outlet. However, the uncertainty on start and end state only affects the sensible heat stored as long as the model describes the battery going from fully liquid to fully solid. The charging time energy fraction method is thus limited to predicting cycles with an initial and final temperature sufficiently different from the phase change range of the used PCM. Expanding the method to partial cycles will require additional measurements which can directly measure the state of charge throughout the charging. As explained by Zsembinszki et al. [48], this is not always feasible.

There is an additional benefit in limiting the initial and final temperature to be sufficiently away from the phase change range. For these cycles, only the overall change in internal energy is required rather than 
the internal energy as a function of temperature. The characterization of PCM materials is a complicated and specialized topic where large discrepancies are sometimes reported in for example the liquid fraction as a function of temperature [15]. However, since only the total sensible and latent heat need to be determined, the uncertainty and difficulty of obtaining the measurement are reduced.

Assumptions 4 and 5 are required to correlate the charging time for a series of energy fractions. Beyne et al. [47] showed that several data sets in literature can be correlated according to Equation 13. However, further tests on additional heat exchanger geometries are required to prove that this applies to all LTES heat exchangers.

Assumption 5 is required to use the same correlation (e.g. Equation 10) for a series of energy fractions which allows to determine the correlation's coefficients as a function of the energy fraction (e.g. Figure 11). Since the total charging time is determined by the duration of all physical processes during the charging, the structure of the total charging time correlation should include the effect of all physical processes. However, it remains necessary to check the error of the charging time correlation as a function of energy fraction (as is done in Figure 10).

The sixth assumption limits the inlet mass flow rate and temperature to constant values. This is required for both the calibration and validation experiments. However in the present case study, deviations from the constant values are present in both types of experiments. The calibrated model however still has predictive value while an adaptation in the use of the model allows to predict the experiment with the mass flow rate jump in Figure 17. The flexibility of the charging time energy fraction method with regard to the inlet temperature and mass flow rate is a topic for future research.

\section{Conclusion}

Latent thermal energy storage heat exchangers are an intensively studied topic in literature. However, this interest has not resulted in predictive models for the outlet temperature of the heat exchanger which can be experimentally fitted.

The present article proposes the charging time energy fraction method as a means to characterize the outlet temperature of LTES heat exchangers. A model is developed for a thermal battery which is charged through a step change in HTF mass flow rate and inlet temperature. It predicts the outlet temperature based on a charging time correlation for a series of energy fractions.

To illustrate the use of the charging time energy fraction method, a thermal battery developed for cold chain transport is characterized. A charging time correlation is developed and fitted for energy fractions between 0.01 and 0.99 . Although the charging cycle deviates from the perfect theoretical cycle, the prediction of the outlet temperature is within $0.45 \mathrm{~K}$ on average except in the initial phases of the experiment. Furthermore, the model allows to predict both the calibration experiments as additional validation experiments with a step change in the mass flow rate.

The charging time energy fraction method is thus a powerful tool to characterize the outlet temperature of LTES heat exchangers. However, several questions regarding the model remain. Firstly, the experimental conditions always deviate from the perfect theoretical conditions. The effect of these deviations on the fitting coefficients is not yet clear and therefore an assessment of the required quality of the calibration experiments is not possible. Secondly, the model is used to predict an experiment with a step change in mass flow rate. The charging time energy fraction model can thus be used to predict 
experiments with non-constant inlet conditions. To fully investigate this potential, additional validation experiments can be performed. These remaining questions are the outlook for further research.

\section{Nomenclature}

Roman symbols

\begin{tabular}{ll}
\hline A & Fitting coefficient for charging time correlation \\
B & Fitting coefficient for charging time correlation \\
C & Specific heat capacity \\
C & Fitting coefficient for charging time correlation \\
D & Fitting coefficient for charging time correlation \\
$f$ & Charging time correlating function \\
$\mathrm{h}$ & Specific enthalpy \\
$h_{l a t}$ & Latent specific heat \\
$\bar{h}_{\text {out }}^{\alpha_{1}, \alpha_{2}}$ & Mean specific enthalpy at the outlet between energy \\
& fractions $\alpha_{1}$ and $\alpha_{2}$ \\
$I_{\Delta T}$ & Integrated average temperature difference between the \\
& measured and predicted outlet temperature. \\
$\mathrm{m}$ & Mass \\
$\dot{m}$ & Mass flow rate \\
$\mathrm{u}$ & Specific internal energy \\
$\mathrm{U}$ & Internal energy \\
$J$ & Stored energy \\
$\dot{Q}_{l o s s}$ & Heat loss \\
$Q_{f}$ & Integrated efflux of energy \\
$\dot{Q}_{f}$ & Efflux of energy \\
$Q_{f, c}$ & Corrected integrated efflux of energy \\
$\dot{Q}_{f}^{\alpha_{1}, \alpha_{2}}$ & Mean efflux of energy between energy fractions $\alpha_{1}$ and \\
$p$ & $\alpha_{2}$ \\
$\mathrm{t}$ & Parameters of the charging time correlation \\
$t_{c}$ & Time \\
$\mathrm{V}$ & Charging time \\
& Volume \\
\end{tabular}

[Ks]

$[\mathrm{kgK}]$

[J/kgK]

$[\mathrm{s}]$

$[\mathrm{kg}]$

$[\mathrm{kg} / \mathrm{s}, 1 / \mathrm{K}] \rightarrow[\mathrm{s}]$

$[\mathrm{J} / \mathrm{kg}]$

$[\mathrm{J} / \mathrm{kg}]$

$[\mathrm{J} / \mathrm{kg}]$

[K]

$[\mathrm{kg}]$

$[\mathrm{kg} / \mathrm{s}]$

[J/kgK]

$[\mathrm{J} / \mathrm{kg}]$

[J]

[W]

[J]

[W]

[J]

[W]

Units depend on correlation

[s]

[s]

$\left[\mathrm{m}^{3}\right]$

Greek symbols

\begin{tabular}{llc}
\hline$\alpha$ & Energy fraction & {$[-]$} \\
$\Delta U$ & Total stored internal energy in a (dis)charging cycle & {$[\mathrm{J}]$} \\
$\Delta T$ & $\begin{array}{l}\text { Temperature difference between the HTF inlet } \\
\text { temperature and the PCM phase change temperature. }\end{array}$ & {$[1 / \mathrm{K}]$} \\
$\Delta T_{S S}$ & $\begin{array}{l}\text { Temperature difference between inlet and outlet of the } \\
\text { HTF after full charging. }\end{array}$ & {$[\mathrm{K}]$} \\
& $\begin{array}{l}\text { Density } \\
\end{array}$ & {$\left[\mathrm{kg} / \mathrm{m}^{3}\right]$} \\
& & \\
\hline HTF & Heat Transfer Fluid & \\
LTES & Latent Thermal Energy Storage & \\
PCM & $\begin{array}{l}\text { Phase Change Materials } \\
\text { RMSD }\end{array}$ & Root Mean Square Deviation
\end{tabular}




\begin{tabular}{ll}
\hline C & Container \\
end & End of the experiment \\
i & Index. \\
in & Liquidus \\
in & Inlet of the HTF \\
out & Outlet of the HTF \\
s & Solidus \\
start & Start of the experiment
\end{tabular}

\section{Aknowledgment}

Wim Beyne received funding from a Ph.D. fellowship strategic basic research of the Research Foundation - Flanders (FWO) (1S08317N). This research was supported by Flanders Make, the strategic research centre for the manufacturing industry, Belgium.

\section{References}

[1] P. Arce, M. Medrano, A. Gil, E. Oró, and L. F. Cabeza, "Overview of thermal energy storage (TES) potential energy savings and climate change mitigation in Spain and Europe," Applied energy, vol. 88, pp. 2764-2774, 2011.

[2] M. K. A. Sharif, A. A. Al-Abidi, S. Mat, K. Sopian, M. H. Ruslan, M. Y. Sulaiman, et al., "Review of the application of phase change material for heating and domestic hot water systems," Renewable and Sustainable Energy Reviews, vol. 42, pp. 557-568, 2015/02/01/ 2015.

[3] P. D. Lund, J. Lindgren, J. Mikkola, and J. Salpakari, "Review of energy system flexibility measures to enable high levels of variable renewable electricity," Renewable and sustainable energy reviews, vol. 45, pp. 785-807, 2015.

[4] Y. Zhao, X. Zhang, and X. Xu, "Application and research progress of cold storage technology in cold chain transportation and distribution," Journal of Thermal Analysis and Calorimetry, vol. 139, pp. 1419-1434, 2020/01/01 2020.

[5] J. Heier, C. Bales, and V. Martin, "Combining thermal energy storage with buildings - a review," Renewable and Sustainable Energy Reviews, vol. 42, pp. 1305-1325, 2015/02/01/2015.

[6] G. A. Farulla, M. Cellura, F. Guarino, and M. Ferraro, "A Review of Thermochemical Energy Storage Systems for Power Grid Support," Applied Sciences, vol. 10, p. 3142, 2020.

[7] O. Teller, J. Nicolai, M. Lafoz, D. Laing, R. Tamme, A. S. Pedersen, et al., "Joint EASE/EERA recommendations for a European energy storage technology development roadmap towards 2030," Joint European Association for Storage of Energy (EASE), 2013.

[8] T.-T. Nguyen, V. Martin, A. Malmquist, and C. A. Silva, "A review on technology maturity of small scale energy storage technologies," Renewable Energy and Environmental Sustainability, vol. 2, p. 36, 2017.

[9] A. Castell and C. Solé, "Design of latent heat storage systems using phase change materials (PCMs)," in Advances in Thermal Energy Storage Systems, ed: Elsevier, 2015, pp. 285-305.

[10] W. Su, J. Darkwa, and G. Kokogiannakis, "Review of solid-liquid phase change materials and their encapsulation technologies," Renewable and Sustainable Energy Reviews, vol. 48, pp. 373391, 2015/08/01/ 2015. 
[11] M. A. Bashir, A. Giovannelli, K. P. Amber, M. S. Khan, A. Arshad, and A. M. Daboo, "Hightemperature phase change materials for short-term thermal energy storage in the solar receiver: Selection and analysis," Journal of Energy Storage, vol. 30, p. 101496, 2020.

[12] K. Faraj, M. Khaled, J. Faraj, F. Hachem, and C. Castelain, "Phase change material thermal energy storage systems for cooling applications in buildings: A review," Renewable and Sustainable Energy Reviews, vol. 119, p. 109579, 2020.

[13] S. Zhang, F. Chen, W. Pan, S. Wang, Y. Jiang, and D. Yuan, "Development of heat transfer enhancement of a novel composite phase change material with adjustable phase change temperature," Solar Energy Materials and Solar Cells, vol. 210, p. 110457, 2020.

[14] Rubitherm. (24/01). Organic PCM - RT. Available: https://www.rubitherm.eu/en/index.php/productcategory/organische-pcm-rt

[15] L. F. Cabeza, Mehling, M., Heat and cold storage with PCM: An up to date introduction into basics and applications: Springer-Verlag Berlin Heidelberg, 2008.

[16] D. Gibb, M. Johnson, J. Romaní, J. Gasia, L. F. Cabeza, and A. Seitz, "Process integration of thermal energy storage systems - Evaluation methodology and case studies," Applied Energy, vol. 230, pp. 750-760, 2018/11/15/ 2018.

[17] P. T. Sardari, D. Giddings, D. Grant, M. Gillott, and G. S. Walker, "Discharge of a composite metal foam/phase change material to air heat exchanger for a domestic thermal storage unit," Renewable Energy, vol. 148, pp. 987-1001, 2020.

[18] A. Shahsavar, A. Goodarzi, H. I. Mohammed, A. Shirneshan, and P. Talebizadehsardari, "Thermal performance evaluation of non-uniform fin array in a finned double-pipe latent heat storage system," Energy, vol. 193, p. 116800, 2020.

[19] C. Zhang, Y. Fan, M. Yu, X. Zhang, and Y. Zhao, "Performance evaluation and analysis of a vertical heat pipe latent thermal energy storage system with fins-copper foam combination," Applied Thermal Engineering, vol. 165, p. 114541, 2020/01/25/ 2020.

[20] A. Cherom Kheirabadi and D. Groulx, The Effect of the Mushy-Zone Constant on Simulated Phase Change Heat Transfer, 2015.

[21] A. Ebrahimi, C. R. Kleijn, and I. M. Richardson, "Sensitivity of numerical predictions to the permeability coefficient in simulations of melting and solidification using the enthalpy-porosity method," Energies, vol. 12, p. 4360, 2019.

[22] R. R. Kasibhatla, A. König-Haagen, F. Rösler, and D. Brüggemann, "Numerical modelling of melting and settling of an encapsulated PCM using variable viscosity," Heat and Mass Transfer, pp. 1-10, 2016.

[23] B. Ameel, C. T'Joen, K. De Kerpel, P. De Jaeger, H. Huisseune, M. Van Belleghem, et al., "Thermodynamic analysis of energy storage with a liquid air Rankine cycle," Applied Thermal Engineering, vol. 52, pp. 130-140, 2013.

[24] H. Huisseune, C. T'joen, P. De Jaeger, B. Ameel, S. De Schampheleire, and M. De Paepe, "Performance enhancement of a louvered fin heat exchanger by using delta winglet vortex generators," International Journal of Heat and Mass Transfer, vol. 56, pp. 475-487, 2013.

[25] H. Huisseune, S. De Schampheleire, B. Ameel, and M. De Paepe, "Comparison of metal foam heat exchangers to a finned heat exchanger for low Reynolds number applications," International Journal of Heat and Mass Transfer, vol. 89, pp. 1-9, 2015.

[26] S. Lecompte, H. Huisseune, M. Van den Broek, S. De Schampheleire, and M. De Paepe, "Part load based thermo-economic optimization of the Organic Rankine Cycle (ORC) applied to a combined heat and power (CHP) system," Applied Energy, vol. 111, pp. 871-881, 2013.

[27] J. Fernandez-Seara, F. J. Uhía, J. Sieres, and A. Campo, "A general review of the Wilson plot method and its modifications to determine convection coefficients in heat exchange devices," Applied Thermal Engineering, vol. 27, pp. 2745-2757, 2007. 
[28] S. Kakac, H. Liu, and A. Pramuanjaroenkij, Heat exchangers: selection, rating, and thermal design, Third ed.: CRC press, 2012.

[29] M. Kind, H. Martin, P. Stephan, W. Roetzel, B. Spang, H. Müller-Steinhagen, et al., "VDI Heat Atlas," 2010.

[30] J. M. Mahdi, S. Lohrasbi, and E. C. Nsofor, "Hybrid heat transfer enhancement for latent-heat thermal energy storage systems: A review," International Journal of Heat and Mass Transfer, vol. 137, pp. 630-649, 2019/07/01/ 2019.

[31] A. Hasan, "Phase change material energy storage system employing palmitic acid," Solar energy, vol. 52, pp. 143-154, 1994.

[32] V. R. Voller and M. Cross, "Estimating the solidification/melting times of cylindrically symmetric regions," International journal of heat and mass transfer, vol. 24, pp. 1457-1462, 1981.

[33] A. Mallow, O. Abdelaziz, and S. Graham, "Thermal charging performance of enhanced phase change material composites for thermal battery design," International Journal of Thermal Sciences, vol. 127, pp. 19-28, 2018.

[34] B. Kamkari and D. Groulx, "Experimental investigation of melting behaviour of phase change material in finned rectangular enclosures under different inclination angles," Experimental Thermal and Fluid Science, vol. 97, pp. 94-108, 2018/10/01/ 2018.

[35] B. Kamkari and H. J. Amlashi, "Numerical simulation and experimental verification of constrained melting of phase change material in inclined rectangular enclosures," International

Communications in Heat and Mass Transfer, vol. 88, pp. 211-219, 2017/11/01/ 2017.

[36] B. Kamkari, H. Shokouhmand, and F. Bruno, "Experimental investigation of the effect of inclination angle on convection-driven melting of phase change material in a rectangular enclosure," International Journal of Heat and Mass Transfer, vol. 72, pp. 186-200, 2014/05/01/ 2014.

[37] A. Sciacovelli, F. Gagliardi, and V. Verda, "Maximization of performance of a PCM latent heat storage system with innovative fins," Applied Energy, vol. 137, pp. 707-715, 1/1/ 2015.

[38] X. Liu, Y. Huang, X. Zhang, C. Zhang, and B. Zhou, "Investigation on charging enhancement of a latent thermal energy storage device with uneven tree-like fins," Applied Thermal Engineering, vol. 179, p. 115749, 2020.

[39] J. Gasia, J. Diriken, M. Bourke, J. Van Bael, and L. F. Cabeza, "Comparative study of the thermal performance of four different shell-and-tube heat exchangers used as latent heat thermal energy storage systems," Renewable Energy, vol. 114, pp. 934-944, 2017.

[40] G. S. Sodhi, A. K. Jaiswal, K. Vigneshwaran, and P. Muthukumar, "Investigation of charging and discharging characteristics of a horizontal conical shell and tube latent thermal energy storage device," Energy Conversion and Management, vol. 188, pp. 381-397, 2019.

[41] A. Castell, M. Belusko, F. Bruno, and L. F. Cabeza, "Maximisation of heat transfer in a coil in tank PCM cold storage system," Applied energy, vol. 88, pp. 4120-4127, 2011.

[42] N. H. S. Tay, F. Bruno, and M. Belusko, "Experimental validation of a CFD and an $\varepsilon-N T U$ model for a large tube-in-tank PCM system," International Journal of Heat and Mass Transfer, vol. 55, pp. 5931-5940, 2012/10/01/ 2012.

[43] Z. Khan and Z. A. Khan, "Thermodynamic performance of a novel shell-and-tube heat exchanger incorporating paraffin as thermal storage solution for domestic and commercial applications," Applied Thermal Engineering, vol. 160, p. 114007, 2019.

[44] Z. Khan and Z. A. Khan, "An experimental investigation of discharge/solidification cycle of paraffin in novel shell and tube with longitudinal fins based latent heat storage system," Energy conversion and management, vol. 154, pp. 157-167, 2017.

[45] S. Thiem, A. Born, V. Danov, A. Vandersickel, J. Schäfer, and T. Hamacher, "Automated identification of a complex storage model and hardware implementation of a model-predictive 
controller for a cooling system with ice storage," Applied Thermal Engineering, vol. 121, pp. 922940, 2017/07/05/ 2017.

[46] R. Raud, M. E. Cholette, S. Riahi, F. Bruno, W. Saman, G. Will, et al., "Design optimization method for tube and fin latent heat thermal energy storage systems," Energy, vol. 134, pp. 585594, 2017.

[47] W. Beyne, K. Couvreur, S. Lecompte, and M. De Paepe, "A technical, financial and CO2 emission analysis of the implementation of metal foam in a thermal battery for cold chain transport," Journal of Energy Storage, vol. 35, p. 102324, 2021/03/01/ 2021.

[48] G. Zsembinszki, C. Orozco, J. Gasia, T. Barz, J. Emhofer, and L. F. Cabeza, "Evaluation of the state of charge of a solid/liquid phase change material in a thermal energy storage tank," Energies, vol. 13, p. 1425, 2020.

[49] H. Moon, N. Miljkovic, and W. P. King, "High power density thermal energy storage using additively manufactured heat exchangers and phase change material," International Journal of Heat and Mass Transfer, vol. 153, p. 119591, 2020.

[50] Y. Zhang, S. Liu, L. Yang, X. Yang, Y. Shen, and X. Han, "Experimental Study on the Strengthen Heat Transfer Performance of PCM by Active Stirring," Energies, vol. 13, p. 2238, 2020.

[51] J. Gasia, J. M. Maldonado, F. Galati, M. De Simone, and L. F. Cabeza, "Experimental evaluation of the use of fins and metal wool as heat transfer enhancement techniques in a latent heat thermal energy storage system," Energy Conversion and Management, vol. 184, pp. 530-538, 2019.

[52] M. Martinelli, F. Bentivoglio, A. Caron-Soupart, R. Couturier, J.-F. Fourmigue, and P. Marty, "Experimental study of a phase change thermal energy storage with copper foam," Applied Thermal Engineering, vol. 101, pp. 247-261, 2016/05/25/ 2016.

[53] S. Kuboth, A. König-Haagen, and D. Brüggemann, "Numerical analysis of shell-and-tube type latent thermal energy storage performance with different arrangements of circular fins," Energies, vol. 10, p. 274, 2017.

[54] M. H. Abokersh, M. El-Morsi, O. Sharaf, and W. Abdelrahman, "An experimental evaluation of direct flow evacuated tube solar collector integrated with phase change material," Energy, vol. 139, pp. 1111-1125, 2017.

[55] M. M. Joybari, F. Haghighat, S. Seddegh, and A. A. Al-Abidi, "Heat transfer enhancement of phase change materials by fins under simultaneous charging and discharging," Energy Conversion and Management, vol. 152, pp. 136-156, 2017.

[56] W. Youssef, Y. Ge, and S. Tassou, "CFD modelling development and experimental validation of a phase change material (PCM) heat exchanger with spiral-wired tubes," Energy conversion and management, vol. 157, pp. 498-510, 2018.

[57] A. M. Abdulateef, S. Mat, J. Abdulateef, K. Sopian, and A. A. Al-Abidi, "Geometric and design parameters of fins employed for enhancing thermal energy storage systems: a review," Renewable and Sustainable Energy Reviews, vol. 82, pp. 1620-1635, 2018/02/01/ 2018.

[58] M. Esapour, A. Hamzehnezhad, A. A. Rabienataj Darzi, and M. Jourabian, "Melting and solidification of PCM embedded in porous metal foam in horizontal multi-tube heat storage system," Energy Conversion and Management, vol. 171, pp. 398-410, 2018/09/01/ 2018.

[59] J. S. Prasad, P. Muthukumar, R. Anandalakshmi, and H. Niyas, "Comparative study of phase change phenomenon in high temperature cascade latent heat energy storage system using conduction and conduction-convection models," Solar Energy, vol. 176, pp. 627-637, 2018.

[60] J. R. Patel and M. K. Rathod, "Thermal performance enhancement of melting and solidification process of phase-change material in triplex tube heat exchanger using longitudinal fins," Heat Transfer-Asian Research, vol. 48, pp. 483-501, 2019. 
[61] Z. Khan, Z. A. Khan, and P. Sewell, "Heat transfer evaluation of metal oxides based nano-PCMs for latent heat storage system application," International Journal of Heat and Mass Transfer, vol. 144, p. 118619, 2019.

[62] P. T. Sardari, D. Grant, D. Giddings, G. S. Walker, and M. Gillott, "Composite metal foam/PCM energy store design for dwelling space air heating," Energy Conversion and Management, vol. 201, p. 112151, 2019.

[63] T. Bauer, "Approximate analytical solutions for the solidification of PCMs in fin geometries using effective thermophysical properties," International Journal of Heat and Mass Transfer, vol. 54, pp. 4923-4930, 2011/11/01/ 2011.

[64] Temper. (2020, 27/01). Heat transfer fluid thermal properties. Available: http://www.temper.se/page/temper/

[65] Y. S. Ranjbaran, S. J. Haghparast, M. Shojaeefard, and G. Molaeimanesh, "Numerical evaluation of a thermal management system consisting PCM and porous metal foam for Li-ion batteries," Journal of Thermal Analysis and Calorimetry, pp. 1-23, 2019.

[66] M. Ghalambaz and J. Zhang, "Conjugate solid-liquid phase change heat transfer in heatsink filled with phase change material-metal foam," International Journal of Heat and Mass Transfer, vol. 146, p. 118832, 2020.

[67] M. lasiello, M. Mameli, S. Filippeschi, and N. Bianco, "Metal foam/PCM melting evolution analysis: Orientation and morphology effects," Applied Thermal Engineering, vol. 187, p. 116572, 2021.

[68] J. Taylor, Introduction to error analysis, the study of uncertainties in physical measurements, 1997. 